\title{
"Borrarán los muros pero no la historia": Relec- turas e Intervenciones a los MHN de Santiago de Chile, estudio de caso en el marco del estallido social (Octubre-Diciembre 2019)
}

"The walls might be erased but not the history": Rereadings and Interventions to the MHN of Santiago, Chile; a case study in the framework of the social outburst (October-December 2019)

\author{
Natalie Martin \\ JIMENA TAPIA \\ Investigadoras independientes, Chile
}

\begin{abstract}
RESUMEN En este artículo se analizan las intervenciones realizadas en diez Monumentos Históricos Nacionales (MHN) del casco fundacional de la ciudad de Santiago en el contexto del estallido social de octubre 2019. Para ello se hizo un registro fotográfico semana a semana hasta fin de año, con el objetivo de caracterizar las intervenciones en su dimensión material y espacial-contextual. Nuestra investigación parte de la premisa que los $\mathrm{MHN}$ son parte de un discurso oficial y representan valores que los consagran como patrimonio. Por lo tanto, las intervenciones dan cuenta de un uso y apropiación específica de este patrimonio y nos permite identificar significados y discursos subalternos, con nuevos agentes, memorias y relatos. Las intervenciones de los MHN y sus Zonas Típicas están poniendo en entredicho las narrativas oficiales, normativas y hegemonizantes, posicionando a los Monumentos como espacios en disputa, donde se configura una nueva forma de entender el presente de los MHN y con ello, el futuro de la relación que establecen con quienes habitan Santiago.
\end{abstract}

PALABRAS CLAVE Patrimonio; estallido social; intervención urbana. 


\begin{abstract}
This article presents an analysis of the interventions carried out on ten national historical monuments $(\mathrm{MHN})$, part of the historical heritage of Santiago, Chile, in the context of October 2019 social outburst . To do this, from October to December 2019, a weekly photographic record was kept, to characterize the interventions in their material and spatial-contextual dimension. Our research starts from the premise that the MHN are part of an official discourse and represent values that consecrate them as heritage; therefore, the interventions account as a specific use and appropriation of this heritage, allowing us to identify deeper discourses and meanings, with new agents, memories and stories. The interventions of the MHN and their Typical Zones are questioning the official, regulatory and hegemonic narratives, thus positioning the Monuments as disputed spaces, configuring a new way of understanding the present of the MHN and with it, the future of the relationship established between them and those who live in Santiago.
\end{abstract}

KEY WORDS Heritage; social outburst, urban intervention.

\title{
Introducción
}

La ciudad de Santiago es la capital política y administrativa del Estado de Chile, aquí residen 6.566.396 personas, lo que corresponde al 37,4\% del total de la población nacional, siendo el núcleo urbano con mayor habitantes (INE, 2017). En los últimos años, la ciudad ha experimentado importantes transformaciones urbanas, y al igual que en las grandes urbes, se han perdido los simbolismos específicos del espacio público y su función se reduce al tránsito de sus habitantes (García Canclini, 1995; Maderuelo, 2001), replicando espacios que no poseen una identidad específica, no lugares (Augé, 1992).

Sumado a esto, en Santiago aún persiste el temor a la ocupación libre y espontánea del espacio público, trauma heredado de la dictadura que ha caracterizado la relación de sus habitantes con la ciudad (Castillo-Gallardo, Peña, Rojas Becker y Briones 2018; Márquez, 2019; Rojo, 2008). Sin embargo, con el estallido social del 18 de octubre del 2019, Chile fue escenario de una masiva protesta social, donde sus habitantes ocuparon las calles para manifestar su rechazo al modelo neoliberal vigente y la displicencia de la clase dirigente. La protesta se materializó en el desarrollo de grandes marchas, "cacerolazos" y disturbios, como destrozos, saqueos e incendios en inmuebles privados, estaciones del Metro y locales comerciales (Salas et al., 2019; Salazar, 2019).

Así, para quienes habitan Santiago, las calles sirvieron como soporte y medio de expresión a través de diversas intervenciones y performances. En este contexto, las Zonas Típicas y los Monumentos Históricos Nacionales (desde ahora MHN) del casco fundacional de la ciudad (Figura 1) se vieron particularmente intervenidos. Para el 
Estado, los MHN son parte de un discurso identitario basado en valores compartidos, no obstante, al estar emplazados en el espacio público, este patrimonio es susceptible a múltiples apropiaciones que desbordan su significado y valor primigenio (Márquez, 2019). Las Zonas Típicas corresponden a agrupaciones de inmuebles representativos de un periodo de tiempo en la historia de una comunidad humana, destacando por su unidad estilística, técnica constructiva y materiales (CMN, s.f.).

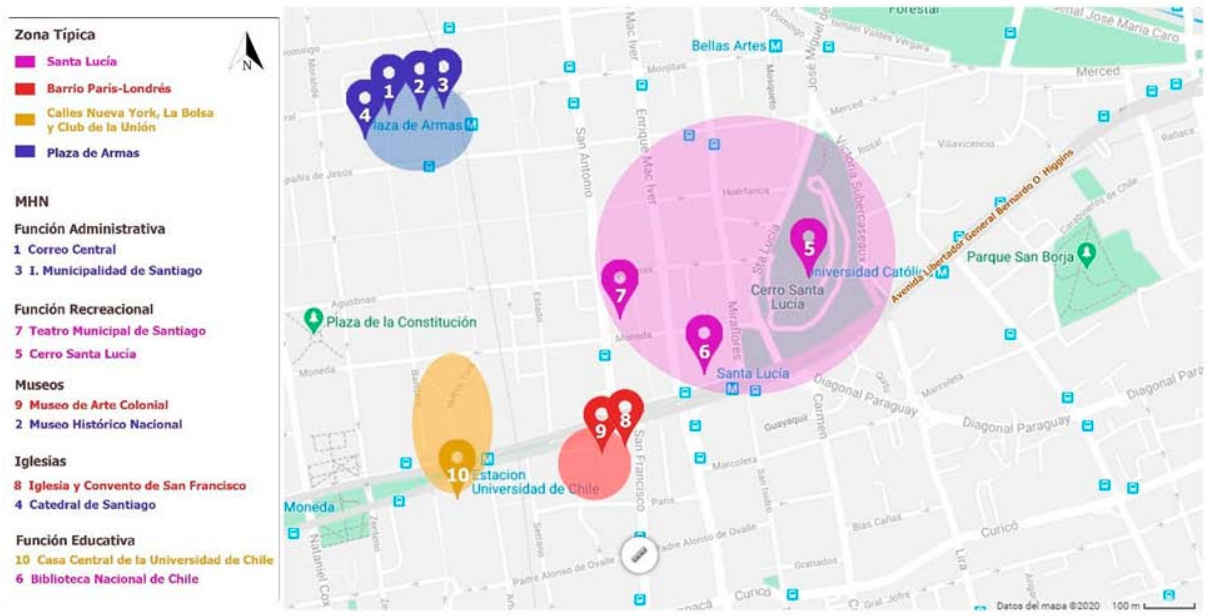

Figura 1. Mapa de MHN revisados, casco fundacional de Santiago. Fuente: Google maps.

La investigación planteada busca caracterizar las intervenciones a los MHN en el desarrollo de la protesta social, en tanto constituyen hitos de la ciudad y estructuras simbólicas de ésta, ya que son parte de un discurso oficial y representan valores hegemónicos que los consagran como patrimonio. Asimismo, los MHN investigados se ubican cercanos y contiguos a la principal avenida del casco histórico de la ciudad y uno de los principales ejes de las manifestaciones, la Avenida Libertador General Bernardo O’Higgins más conocida como "La Alameda" (Figura 1), que tiene su inicio en Plaza Baquedano, renombrada "Plaza de la Dignidad" y epicentro de las protestas.

La metodología consistió en el registro fotográfico de la fachada de estos inmuebles y de la Zona Típica en la que se ubican. El periodo de tiempo abordado consideró las semanas comprendidas entre el 18 de octubre hasta el 31 de diciembre del año 2019, analizando sus modificaciones a lo largo de este tiempo.

Se revisaron diez MHN emplazados en la comuna de Santiago y distribuidos en cuatro Zonas Típicas: Plaza de Armas, Santa Lucía, Barrio París-Londres y calles Nueva York, La Bolsa y Club de la Unión. Los monumentos se agruparon considerando las funciones que cumplen actualmente: administrativa que comprende Correo Central y la I. Municipalidad de Santiago; función recreacional con el Teatro Municipal de Santiago y Cerro Santa Lucía; inmuebles que son museos, Museo de Arte 
Colonial y Museo Histórico Nacional; inmuebles que son iglesias, Iglesia y Convento de San Francisco y Catedral de Santiago; e Inmuebles con función educativa que integran la Casa Central de la Universidad de Chile y Biblioteca Nacional de Chile.

La premisa que guía nuestra investigación, se basa en que las vivencias y acciones acontecidas en el espacio público dejan huellas materiales, las que a su vez van configurando una manera concreta de usar y construir la ciudad (Aliste, 2008). Lo anterior cobra relevancia, si consideramos que el estallido social del 18 de octubre se ha perfilado como la revuelta más extendida, significativa y violenta que ha experimentado Chile a lo largo de toda su historia (Salazar, 2019) y que tuvo como consecuencia el inicio del proceso para redactar una nueva Constitución, aprobado en el plebiscito ciudadano llevado a cabo un año después (25 de octubre del año 2020), debido a su aplazamiento por la pandemia mundial del Covid-19, momento en que fue escrito este texto.

Por lo tanto, abordar este fenómeno social mediante las intervenciones a los MHN, posibilita una vía de acceso para conocer las demandas y reflexiones que se instalaron en sus muros, y a partir de éstas, comprender la incidencia que tienen los discursos dominantes, de acuerdo a la relación que entablan quienes habitan la ciudad con su patrimonio. En este contexto, una perspectiva arqueológica nos permite adentrarnos en las materialidades más allá de su objetualidad, sino como lienzos urbanos donde cobra relevancia lo que se dice, cómo se dice y cuál es la relación de ello con la carga histórica y valórica que representa cada monumento, develando redes de significados en los que la arqueología también ha tenido gran incidencia.

\section{La ciudad de Santiago y su patrimonio: uno de los escenarios del estallido social}

a) Estallido social: crónica de una revuelta anunciada

El estallido social del 18 de octubre del 2019 se ha perfilado como la oleada de manifestaciones más multitudinarias de la historia nacional, donde los chilenos y chilenas se trasladaron a las calles exigiendo cambios estructurales en materia económica, social y de derechos (Salas et al., 2019). El antecedente directo para que el estallido social detonara fue el alza de 30 pesos en el pasaje del transporte urbano Metro, lo que generó masivas evasiones de su pago durante la semana. Esta iniciativa tendrá como resultado una revuelta colectiva y autoconvocada, cuyo inicio se establece el viernes 18 de octubre con el colapso del sistema de transportes y la quema de algunas estaciones de Metro. Con ello, surge uno de los lemas más destacados de las manifestaciones, "No son 30 pesos, son 30 años" en alusión a la herencia de la Dictadura y su implicancia en el sistema económico (Adriazola, 2019).

En efecto, el golpe de estado de 1973 constituye una de las grandes heridas en la memoria nacional, lo que ha determinado la configuración de la historia chilena contemporánea (Castillo-Gallardo et al., 2018). El modelo neoliberal instaurado con 
la Constitución de 1980, funda una nueva forma de entender la relación entre el Estado y la sociedad civil, con la subsecuente despolitización de ésta (Fair, 2008) y la descentralización del poder del Estado hacia los capitales privados (Calvento, 2006). Con el retorno a la democracia, el escenario antes que modificarse se agudiza, no sólo porque dicha carta sigue vigente, sino también porque las modificaciones que sufre no han hecho sino aumentar la desigualdad (Matus, 2019; Vargas, 2007).

Dicho escenario propicia la aparición de distintos movimientos que han dejado en evidencia el descontento de la población nacional, como por ejemplo el 'Movimiento de Pobladores en Lucha, el Movimiento de los Pingüinos, NO + AFP y las demandas del pueblo Mapuche por su autodeterminación y recuperación de sus tierras, sólo por citar algunos (Salas et al., 2019), los que en años anteriores se han volcado a las calles debido a la nula posibilidad de manifestarse por vías oficiales (Rojo, 2008). Es por lo anterior, que el 18 de octubre del año 2019 quienes habitan Chile salen a las calles para exigir cambios estructurales en materia económica, social y de derechos. Aunque el estallido fue caracterizado como una manifestación voluntaria y apartidista, se pueden identificar algunas demandas transversales, como la redacción de una nueva Constitución; la reforma del sueldo mínimo y a los fondos de pensiones; la mejora del sistema de salud pública, el fin al sobreendeudamiento en materias de educación; el derecho legítimo sobre bienes de uso público y recursos naturales, entre otras (Salas et al., 2019).

De esta manera, el estallido social se ha consagrado como una de las revueltas más violentas en la historia de Chile (Salazar, 2019). Ciertamente, la violencia y su uso práctico ha sido una de las tónicas que marcaron la trayectoria del estallido, con medidas represivas que costaron la vida y visión de un gran número de compatriotas (Peñaloza, 2019). Pero cuando hablamos de violencia no sólo hacemos alusión a las medidas tomadas por el ejecutivo para detener la libre manifestación ciudadana, sino también en cómo se han abordado y catalogado éstas. Una de las consecuencias del estallido ha sido la modificación del concepto de terrorismo, surgido de los discursos del Estado y aplicado a los manifestantes, donde se exaltan las nociones de miedo, seguridad y guerra en contraposición a la de "buen ciudadano" (Navarro y Tromben, 2019). En aquel escenario, aparece un grupo de personas autodenominado "chalecos amarillos", cuyo cometido fue la protección o restauración de inmuebles públicos y privados afectados durante las manifestaciones (Correa, 2019).

Durante los dos primeros meses del estallido, los discursos presidenciales estuvieron dirigidos a la justificación del uso de la fuerza por agentes del Estado (Navarro y Tromben, 2019). De esta manera, mientras la violencia física en contra de los manifestantes iba en aumento, el gobierno ejercía una violencia simbólica (Bourdieu, 1991) apoyándose en los medios de comunicación y levantando una serie de narrativas donde se exalta el rol de carabineros y se recrimina la protesta. A pesar de esto, las 
personas se vuelcan a las calles para protestar, observándose intervenciones materiales con un contenido comunicativo intencional (Martínez, 2019).

En base a lo anterior, podemos ver que la ciudad presenta dos características complementarias y contradictorias, por un lado es un espacio de control que norma flujos y comportamientos; pero también se presenta como un espacio subversivo con diversos usos e intervenciones que la modifican y resignifican (Aliste, 2008; Soja, 2011), incidiendo en la afección que las personas tienen con ésta y posibilitando un punto de encuentro y enunciación entre quienes la habitan (Maderuelo, 2001). Por lo tanto, la ciudad es un producto social complejo, donde no sólo lo social configura lo espacial, sino que lo espacial configura lo social (Soja, 2011).

b) El patrimonio de Santiago

La ciudad de Santiago fue fundada por los colonizadores españoles en 1541, en el territorio que limita con los dos brazos del río Mapocho, sector que hoy conocemos como el área fundacional de la ciudad (Benavides, 1988). Consolidado Chile como país independiente, la arquitectura pública del área fundacional de la ciudad sienta sus bases en la emulación de las grandes construcciones europeas neoclásicas y a partir de esta similitud comienza a gestarse un imaginario en torno a la ciudad como paisaje urbano (Gross, 1991). Desde inicios del siglo XXI Santiago ha experimentado un aumento sostenido de su población con los proyectos inmobiliarios en altura, reactivando espacios de exclusión o hacinamiento en el centro de la capital, así como la urgencia de preservación de espacios históricos y patrimoniales (Paulsen, 2014).

En Chile el patrimonio se vuelve un tema de interés durante la Dictadura, periodo en el cual estos bienes resultan una herramienta útil para encarnar el poderío del Estado y su identidad nacional (Ayala, 2014; Boccara y Ayala, 2011). Las narrativas hegemónicas asociadas al patrimonio han privilegiado su antigüedad y filiación con la clase dominante, con una escasa consideración de los actores vinculados a éste (Boccara y Ayala, 2011). Lo anterior, se ha traducido en que actualmente en Chile, si bien el patrimonio, encarna un ideal de nación y de lo que implica ser ciudadano, también se configuran visiones subalternas de lo que éste significa. Entonces, pese al discurso que se instala como oficial en torno al patrimonio, un mismo bien puede ser considerado tal por otros argumentos y valores (Smith, 2006). Por consiguiente, el patrimonio siempre está en potencial de ser, no es algo estático y su configuración depende tanto del discurso hegemónico que lo determina, así como de quienes establecen ciertas dinámicas de relación con éste (Harrison, 2013).

De esta manera, el patrimonio, o mejor dicho lo que hoy consideramos patrimonio no nace para dichos fines, pues antes de esta consideración cumplió otro rol y es la carga valórica actual lo que lo determina como tal, por tanto, en él se acoplan el presente y el pasado, la memoria y el olvido, lo vivido y lo anhelado (Criado-Boado y Barreiro, 2013; Hernández, 2008). Desde esta línea de análisis, el patrimonio antes 
que remitir a un bien en sí mismo se esboza como una categoría de pensamiento moderno, del que se apropian las entidades hegemónicas para plasmar su ideología y ejercer una dominación simbólica sobre las poblaciones emparentadas con estos bienes (Criado-Boado y Barreiro, 2013; Hamilakis, 2007; Harrison, 2013).

c) Los MHN y Zonas Típicas de Santiago como lienzos urbanos

Los MHN y las Zonas Típicas son declarados por decreto supremo del Ministerio de Educación, generalmente en respuesta a una solicitud previa de personas, comunidades u organizaciones (Ley $\mathrm{N}^{\circ} 17.288,2011$ ). Por ende, si bien los ciudadanos tienen incidencia en poder postular los bienes que consideran significativos por su valor histórico, artístico o cultural, en última instancia es el Estado quien toma la decisión y despliega todo su poderío para hacer cumplir con las normas que determinan la interacción con dichos bienes (Márquez, Rozas y Arriagada, 2014).

La importancia dada por el gobierno a los MHN, radica en que estos inmuebles estarían delimitando urbanística, material e ideológicamente a la ciudad, pues actúan como emblemas que anclados en el centro fundacional de la ciudad, dan curso al imaginario en torno a una memoria común, posibilitando, aunque sea simbólicamente, la cohesión social (Márquez et al., 2014). Dichos inmuebles poseen una historia que los distingue dentro del entramado urbano, por lo que su intervención puede enunciar conflictos que acarrea la existencia de un discurso oficial frente a otras narrativas (Márquez, 2019).

De acuerdo a la declaración del Consejo de Monumentos Nacionales (CMN) actualizada en enero del año 2020, en Chile actualmente existen 1079 MHN de tipo inmueble, de los cuales 270 se localizan en la Región Metropolitana y 112 en la comuna de Santiago, lo que corresponde al 10,4\% de éstos. En Chile hay 146 Zonas Típicas de las cuales 48 se ubican en la Región Metropolitana y 20 en la comuna de Santiago, o sea un $13,7 \%$ (CMN, 2020a).

Posterior al estallido social, el Informe de la Secretaría Técnica del CMN entregado el 16 de enero del año 2020, informa que en la región Metropolitana se registran el mayor número de MHN y Zonas Típicas afectadas. El Ministerio de las Culturas, las Artes y el Patrimonio, Ministerio de Vivienda, MOP (Ministerio de obras públicas) y SUBDERE (Subsecretaría del Desarrollo Regional y Administrativo), elaboraron en conjunto un catastro de los daños a bienes patrimoniales para su reparación y limpieza. Los daños más recurrentes fueron rayados, rotura de vidrios, incendios o amagos de incendio, cuyo grado de afectación fue diverso (CMN, 2020b).

\section{Propuesta para abordar Qué nos dicen las intervenciones a los MHN}

Esta investigación presenta un enfoque metodológico cualitativo descriptivo, basado en la caracterización de las intervenciones que experimentaron diez MHN, emplazados en cuatro Zonas Típicas del casco fundacional de la comuna de Santiago. Para 
ello se realizó un registro fotográfico una vez por semana de las fachadas y entornos de estos inmuebles, en el período comprendido desde el 18 de octubre hasta el 31 de diciembre del año 2019.

Los inmuebles revisados en este artículo se agruparon según la función que cumplen en la actualidad de acuerdo a la declaración de monumentos nacionales. Éstas corresponden a: función educativa, recreativa, administrativa, religiosa y museos. Cabe destacar que si bien entendemos que las intervenciones fueron ejecutadas por sujetos o colectivos, nuestro objetivo se centra en revisar las intervenciones a los MHN y cómo dialogan con éstos.

Las intervenciones fueron analizadas en base a dos aspectos, por un lado, en relación a sus características materiales, es decir, la manera en cómo se hacen y las técnicas que se utilizan, lo cual puede tener implicancias en su durabilidad en los soportes o evidenciar una intencionalidad de ejecución; afectando la percepción o estética de los monumentos, por ejemplo: pintura, rayados, lienzos, o acciones que añaden o quitan elementos, entre otros. Por otro lado, se analizó aquello que dicen, refieran o consignen las intervenciones desde el punto de vista conceptual, lo cual puede establecer una relación con el MHN o Zona Típica (contexto) donde se inscriben.

Con la finalidad de caracterizar estas intervenciones, se establecieron dos dimensiones: 1) Material: que alude a la Técnica de ejecución y al Tipo de consigna, es decir a lo referido en éstas, y 2) Espacial-Contextual: que establece la relación que tienen las intervenciones de estos monumentos con su Zona Típica, y con la cronología y desarrollo del estallido social. Para llevar a cabo dicha tarea se utilizó una ficha de registro, orientada a evaluar semana a semana cómo se iba comportando el monumento y su Zona Típica, así como también, se inscribieron los sucesos más destacados que se iban desarrollando, como se ejemplifica en la Tabla 1. 
Tabla 1. Ejemplo de Ficha de registro semanal para el análisis de las intervenciones a los MHN.

\begin{tabular}{|c|c|l|}
\hline \multicolumn{2}{|c|}{ Fecha: Semana 2 } & \multicolumn{1}{|c|}{ MHN } \\
\hline \multirow{4}{*}{ Dimensión Material } & $\begin{array}{c}\text { Técnica de } \\
\text { ejecución }\end{array}$ & $\begin{array}{l}\text { Rayado, Cartel, Paste up, Grafiti, Mural, } \\
\text { Sticker, Esténcil, Chapa, Mural, Perfor- } \\
\text { mance, Instalaciones (añadidura de otros } \\
\text { elementos) e Intervención a monumento } \\
\text { público (estatua). }\end{array}$ \\
\hline \multirow{5}{*}{$\begin{array}{c}\text { Dimensión } \\
\text { Espacial-Contextual }\end{array}$} & $\begin{array}{c}\text { Tipo de } \\
\text { consigna }\end{array}$ & $\begin{array}{l}\text { Ejemplo: Aparecen consignas referidas a la } \\
\text { recriminación al actuar de fuerzas de orden } \\
\text { público y a la dictadura. }\end{array}$ \\
\hline & $\begin{array}{c}\text { Intervenciones } \\
\text { en la Zona }\end{array}$ & $\begin{array}{l}\text { Ejemplo: Rayado en las piletas de la plaza } \\
\text { contigua con demandas sociales. Además, } \\
\text { se identifican carteles de factura casera con } \\
\text { consignas sobre pueblos originarios (au- } \\
\text { tonomía Mapuche y Kultrún) y veganismo. }\end{array}$ \\
\cline { 2 - 4 } & $\begin{array}{c}\text { Cronología con } \\
\text { el Estallido } \\
\text { Social }\end{array}$ & $\begin{array}{l}\text { Ejemplo: Las intervenciones aluden al cam- } \\
\text { bio de gabinete (28-10-2019) y al uso de } \\
\text { Mentholatum (31-10-2019) por parte de car- } \\
\text { abineros. El resto de los sucesos acontecidos } \\
\text { durante la semana no son referidos. }\end{array}$ \\
\hline
\end{tabular}

Respecto a la variante de Tipo de consignas, fueron revisadas mediante un análisis de contenido, recurriendo a categorías para su agrupación y análisis. Cabe mencionar que el tratamiento dado a las consignas fue una vía para operacionalizar su análisis y revisión, entendiendo que antes que un conjunto de vocablos, corresponden a demandas y exigencias ciudadanas. Algunos ejemplos de las categorías trabajadas se observan en la Tabla 2.

Tabla 2. Tipo de consigna intervenida en los MHN y su Zona Típica.

\begin{tabular}{|c|c|}
\hline \multicolumn{2}{|r|}{ Tipo de consigna } \\
\hline $\begin{array}{l}\text { Consignas del estallido y posi- } \\
\text { cionamiento ante éste }\end{array}$ & $\begin{array}{l}\text { Evade", "Lucha”, "No son } 30 \text { pesos, son } 30 \text { años", } \\
\text { "Queremos Paz", "Resiste”, entre otras. }\end{array}$ \\
\hline Demandas sociales & $\begin{array}{l}\text { "Educación para todes", "Fin al CAE", "No + AFP", } \\
\text { "No + Sename", "Salud Digna", entre otras. }\end{array}$ \\
\hline $\begin{array}{l}\text { Recriminación al actuar de las } \\
\text { fuerzas armadas y de orden } \\
\text { público }\end{array}$ & $\begin{array}{c}\text { "Aborta al Paco", “ACAB”, "Carabineros de \$hile”, } \\
\text { "Milico Asesino", "Milicos devuélvanse a sus cuarte- } \\
\text { les", entre otras. }\end{array}$ \\
\hline
\end{tabular}




\begin{tabular}{|c|c|}
\hline Denuncia de víctimas & $\begin{array}{l}\text { De manera directa (visibilizando sus nombres y/o } \\
\text { rostros) o de manera indirecta (mencionando los da- } \\
\text { ños causados y/o el número de personas afectadas). }\end{array}$ \\
\hline Estado & $\begin{array}{l}\text { "Cárcel para Chadwick", "Estado Asesino", "Muerte } \\
\text { al Estado", "Piñera come pizza", "Piñera renuncia", } \\
\text { entre otras. }\end{array}$ \\
\hline Dictadura & $\begin{array}{l}\text { "1973=2019", "La dictadura aún dura”, "Back to 1973", } \\
\text { "Piñechet" "Que se acabe la dictadura", entre otras. }\end{array}$ \\
\hline Pueblos originarios & $\begin{array}{l}\text { "Con la fuerza de nuestros ancestros", "Des- } \\
\text { colonízate", "Newen", "Resiste como Mapuche", } \\
\text { "Wallmapu libre", entre otras. }\end{array}$ \\
\hline Feminismo & $\begin{array}{l}\text { "Aborto libre", "El violador eres tú", "Fuerza femini- } \\
\text { sta", "La revolución será feminista o no será", "Muerte } \\
\text { al patriarcado", entre otras. }\end{array}$ \\
\hline Veganismo & $\begin{array}{l}\text { "-Carne + Tofu”, "Carne es muerte”, “Go vegan”, "Lib- } \\
\text { eración Animal”, "Vegan”, entre otras. }\end{array}$ \\
\hline $\begin{array}{l}\text { Alusiones a la función que } \\
\text { cumple el monumento }\end{array}$ & $\begin{array}{l}\text { Consignas referidas a la función establecida para } \\
\text { cada MHN. }\end{array}$ \\
\hline Otros & $\begin{array}{c}\text { Consignas no consideradas en las categorías anteri- } \\
\text { ores. }\end{array}$ \\
\hline
\end{tabular}

\section{Resultados}

Dentro de las características que comparten todos los monumentos revisados, la técnica predominante mediante la cual son intervenidos es el rayado, destacando también los carteles e instalaciones de otros elementos. A grandes rasgos, en ninguno se evidencia una relación directa entre las intervenciones con la cronología del movimiento, sin embargo, se destacan tres hitos, cuyas consignas se apoderaron de los muros de Santiago: La conmemoración del asesinato de Camilo Catrillanca el 14 de noviembre ${ }^{1}$, la intervención del colectivo "Las Tesis" desde el 25 de noviembre ${ }^{2}$ en Santiago y el día del ACAB el 13 de diciembre ${ }^{3}$. Pese a ello, cada espacio presenta sus características particulares, las que expondremos a continuación.

1. Camilo Catrillanca, comunero Mapuche de la Región de la Araucanía, falleció de un impacto de bala el 14 de noviembre de 2018, producto de un operativo policial. Para conmemorar un año de su asesinato, se convocó a varias manifestaciones a lo largo del país. Los carabineros de fuerzas especiales involucrados en su muerte, aún están en proceso judicial (Radio UChile, 2019).

2. El colectivo feminista "Las Tesis" creó la performance "Un violador en tu camino", para manifestarse en contra de la violencia hacia la mujer además de denunciar la falta de justicia en crímenes sexuales, donde en muchos casos se culpabiliza a las mujeres. Su primera realización en el contexto del estallido social fue el día 20 de noviembre en Valparaíso, unos días después se realiza en Santiago y varias ciudades del país, con lo cual se hace viral en redes sociales y es replicada a lo largo del mundo por miles de mujeres (BBC, 2019). 
a) Inmuebles con función administrativa

Se revisó el Correo Central y la I. Municipalidad de Santiago, ambos edificios declarados MHN en 1976 y ubicados en la Plaza de Armas, pero separados por el Museo Histórico Nacional. La Zona Típica de la Plaza de Armas nunca dejó de funcionar como plaza, y si bien en un primer momento estuvo resguardada por carabineros, se retiran las semanas próximas a las celebraciones de fin de año.

El Correo Central se emplaza en el sitio que desde 1820 fuera el Palacio de los presidentes y a causa de un incendio en 1881 se dio curso a la construcción del edificio de Correo, que actualmente es la sede principal de Correos de Chile y alberga en su interior el Museo Postal y Telegráfico (CMN, 1976a). En el lugar donde hoy se encuentra la I. Municipalidad de Santiago, durante la Colonia funcionó el Cabildo y la Cárcel Pública, demolidos a fines del siglo XVIII. En 1790 se construyó un nuevo Cabildo, posteriormente denominado Municipalidad, lo que determinó su uso hasta nuestros días (CMN, 1976b).

A lo largo del estallido social, ambos edificios no presentaron mayores intervenciones, contrario a lo que sucedió con la Plaza de Armas y sus locales comerciales. Sólo en las últimas semanas se observaron dos pequeños rayados en el Correo Central, que corresponden a consignas de tipo personales en el código chapas. Por su parte en la I. Municipalidad se registró una bomba de pintura en tono celeste arrojada a la fachada a un mes del estallido, cuya huella material no fue borrada a lo largo del registro y en la puerta de la oficina de turismo (que ocupa un costado de la Municipalidad), se identifica la aparición del dibujo de un kultrún.

En lo que respecta a la Zona Típica de la Plaza de Armas, se observó un número considerable de intervenciones del tipo rayado, destacando las consignas que aluden al uso desmedido de la fuerza por parte de carabineros y referencia a las víctimas. También se recurre al rayado de la calzada, sobresaliendo las intervenciones sobre las placas de metal que conmemoran la fundación y expansión de Santiago, frente al edificio de la Municipalidad. Estas placas son intervenidas con el dibujo de un kultrún y la declaratoria "Wallmapu libre" (Figura 2). Las intervenciones registradas en estos monumentos no fueron borradas y las labores de limpieza en este espacio recién comenzaron a dos meses del estallido social.

3. ACAB, es el acrónimo en inglés de "All Cops Are Bastard". El término proviene de la cultura underground angloparlante y se popularizó en 1982 cuando la banda "The 4-Skins" (género Oi!, derivado del punk), tituló una canción "A.C.A.B” en el álbum "The Good, The Bad and The 4-Skins", que en su portada posicionaba a los policías como los malos (The Bad). Además, el número 1312 se le asocia a esta sigla debido al orden alfabético de sus letras, por lo que el 13 de diciembre se le atribuye como su día (Chilevisión noticias, 2019). 

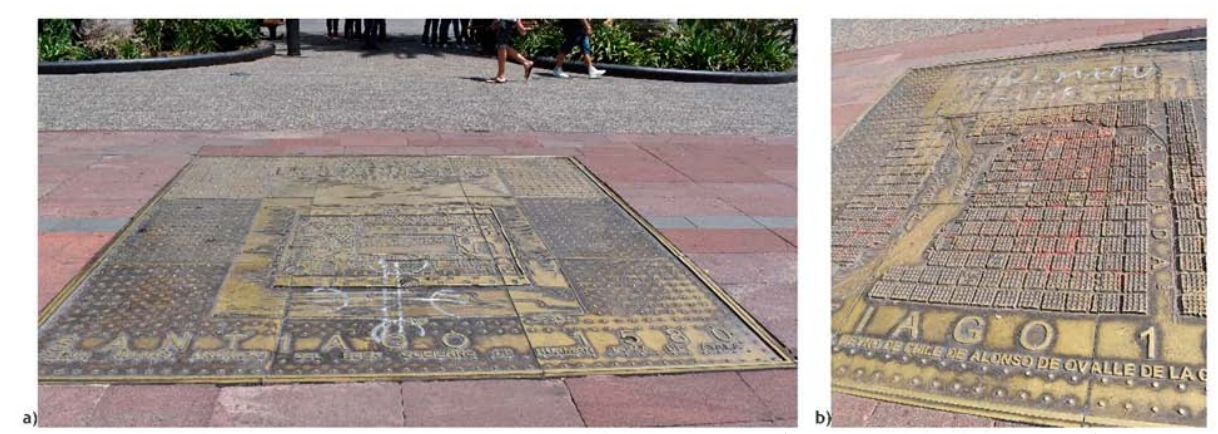

Figura 2. Intervención a placas de la Plaza de Armas. a) Dibujo de Kultrún (18-11-19).

b) Wallmapu libre (24-11-19).

Aunque en esta Zona Típica inicialmente aparecen consignas variadas, a medida que avanza el tiempo, apuntan principalmente a las demandas del pueblo Mapuche y se vuelven más recurrentes al acercarse la conmemoración del asesinato de Camilo Catrillanca. Por lo tanto, las intervenciones y consigas hacen relación a la plaza como el lugar fundacional de Santiago, mas no en relación a la función específica de los MHN revisados.

b) Inmuebles con función recreacional

Se registraron el Cerro Santa Lucía y el Teatro Municipal de Santiago, ambos ubicados en la Zona Típica del barrio Santa Lucía. El Cerro Santa Lucía se mantuvo abierto a visitantes aunque con restricción de horarios e ingresos, por su parte, el Teatro Municipal se cierra y cancela sus actividades hasta diciembre.

El Cerro Santa Lucía corresponde a uno de los hitos arquitectónicos más destacados del casco histórico de Santiago, declarado MHN en el año 1983. Fue fundado como atractivo recreativo en 1872, cuando el intendente Benjamín Vicuña Mackenna implementa una serie de mejoras urbanas para celebrar el centenario de la nación. Presenta tres accesos: el principal por La Alameda, por calle Santa Lucía y perpendicular a la calle José Miguel de la Barra (Duarte, 2003).

Las tecnologías más utilizadas en las intervenciones del Cerro Santa Lucía corresponden a rayados y luego se suman carteles. Desde la primera semana del estallido social, las consignas en la cara de la Alameda se refieren a las implicancias de la conquista española y a la figura de los colonizadores, además de otras que incitan a la lucha y demandas sociales. A partir de la tercera semana, las consignas rayadas dan cuenta de las víctimas en un tono de denuncia, entregando sus nombres y visibilizando sus rostros. Además, se interviene la carta de Pedro de Valdivia, grabada sobre piedra a un costado de la entrada principal, resaltando el nombre prehispánico del cerro (Huelén), la que primeramente es rayada con alusiones descolonizadoras y a un mes del estallido social se elabora un dibujo que enumera a las víctimas de mu- 
tilaciones oculares consecuencia del actuar represivo de carabineros, número que es actualizado antes de las celebraciones de fin de año (Figura 3).
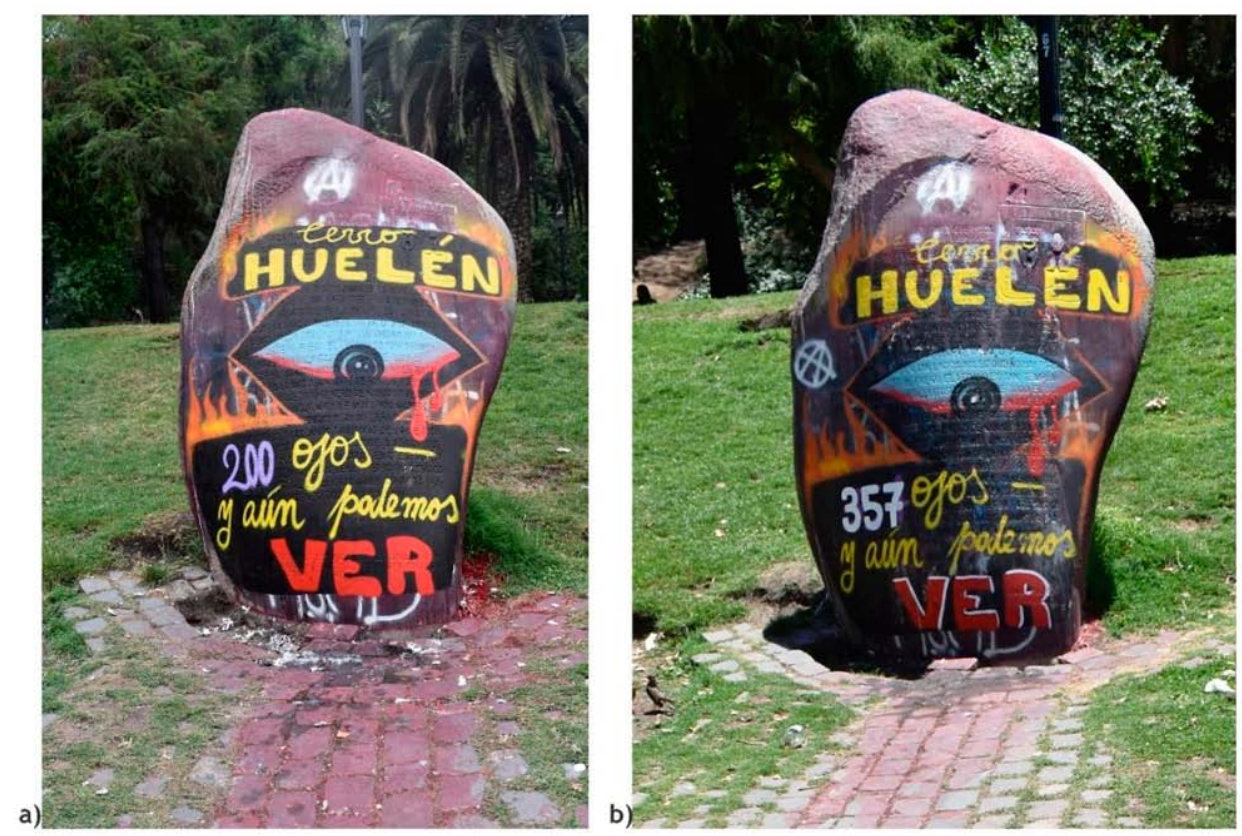

Figura 3. Intervención sobre carta de Pedro de Valdivia. Fotografías tomadas a) 1811-19 y b) 22-12-19, número de víctimas de mutilación ocular es actualizado.

A lo largo de la investigación constatamos cinco labores de limpieza con el repintado de la entrada principal, pese a ello, los muros presentan semana a semana una gran cantidad y densidad de rayados, los que en algunos casos se superponen. De hecho, parte de las consignas con las cuales se reinterviene este espacio aluden al borrado y limpieza de muros, así como al renombramiento del cerro (Figura 4). 

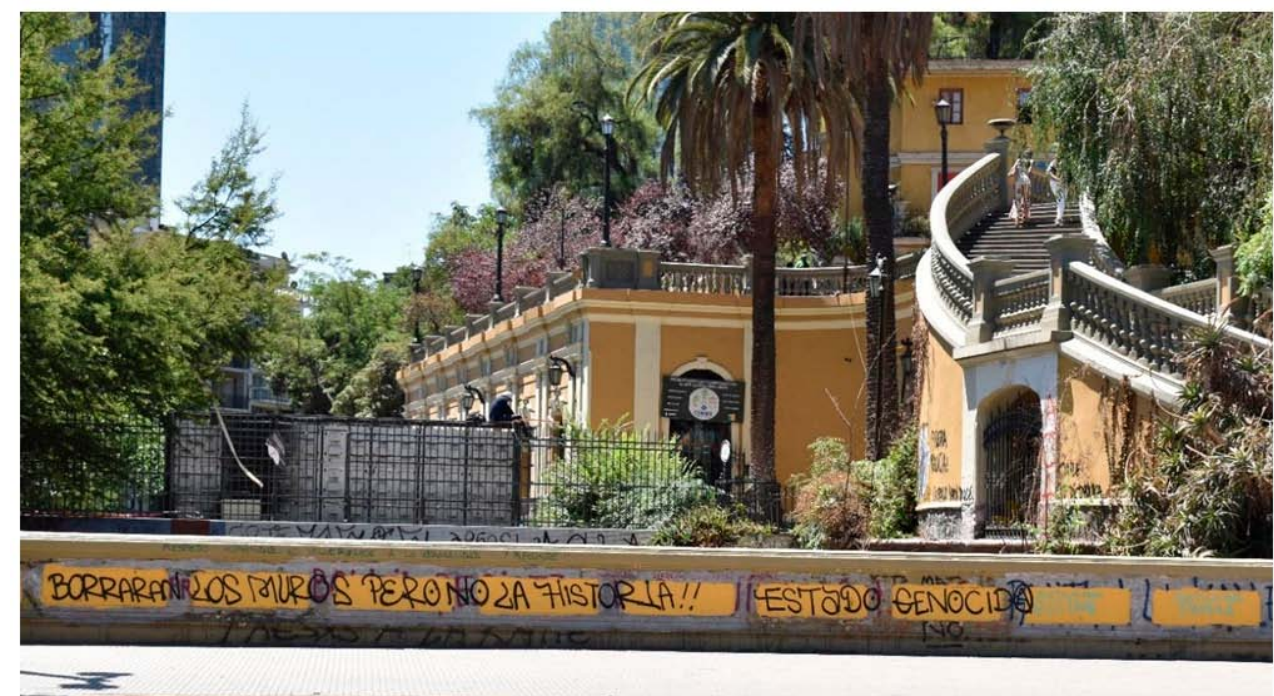

Figura 4. Intervención aludiendo a las labores de repintado, se lee: "Borrarán los muros pero no la historia!! Estado genocida" (04-12-19).

En cuanto a la cara del Cerro que apunta a la calle Santa Lucía, es intervenida de forma continua mediante rayados en las estructuras urbanas (postes y calzada), así como también las estatuas que están en el acceso. Éstas corresponden a hombres con indumentaria europea colonial, a las que se les van sumando rayados semana a semana, destacando dibujos de kultrún, la palabra "colonizadores" y pintura en sus ojos en alusión a las víctimas de mutilación del globo ocular. Finalmente, en la segunda quincena de diciembre estas estatuas son retiradas (Figura 5).
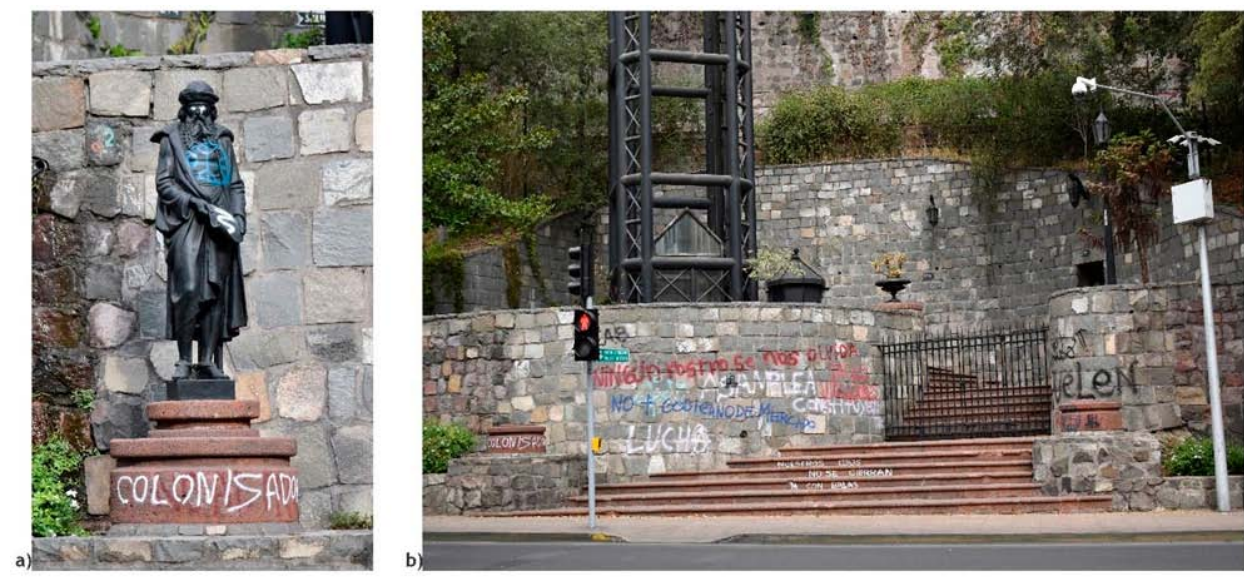

Figura 5. Cerro Santa Lucía, entrada por calle homónima. a) Intervención a una de las estatuas (11-11-19). b) Estatuas son retiradas (22-12-19). 
El Teatro Municipal de Santiago es el centro cultural más antiguo del país, inaugurado en 1857 y emplazado en el lugar que ocupó la Universidad Real de San Felipe. Tras un incendio, fue reconstruido y reinaugurado en 1873 como Teatro y declarado MHN el año 1974 (CMN, 1974a).

Desde la primera semana se registraron rayados tanto en el frontis del Teatro $\mathrm{Mu}$ nicipal como por la entrada de la calle San Antonio, destacando las consignas del estallido, más otras que apuntaron a la recriminación del actuar de las fuerzas de orden público y a la reivindicación de pueblos originarios. En la fachada principal no se registra gran cantidad de rayados y varios de éstos fueron realizados con bolígrafo, por lo cual su visibilidad es baja; en cambio en la entrada por San Antonio hay mayor densidad de éstos. Por su parte, los alrededores del Teatro Municipal no se intervinieron mayormente y se focalizaron en las estructuras urbanas y en las cortinas metálicas de bancos y locales comerciales; sobresaliendo consignas referidas al Estado, la recriminación al actuar de fuerzas de orden público, la dictadura militar y alusiones al pueblo Mapuche (dibujos de Kultrún).

En suma, en los inmuebles con función recreacional se evidencia una reivindicación de lo prehispánico y lo Mapuche, donde el tópico de la colonización y el colonizador aparece con fuerza desde las primeras intervenciones. Así, en ambos espacios se instala la temática de pueblos originarios, lo cual si bien podría asociarse a la cercanía entre los inmuebles, también corresponde a una reflexión en torno a su pasado como instancias recreativas de la élite. Mas, la única fachada que es silenciada constantemente es la cara del Cerro Santa Lucía que da a la Alameda.

c) Inmuebles que funcionan como museos

Los museos investigados fueron el Museo de Arte Colonial y el Museo Histórico Nacional, el primero se ubica en la Zona Típica del Barrio París-Londres y el segundo en la Plaza de Armas, justamente en medio de los dos inmuebles anteriormente revisados. Ambos estuvieron cerrados al iniciar el estallido social, el de Arte Colonial reabrió a un mes del estallido, mientras que el Histórico permaneció cerrado y sus trabajadores estuvieron en paro desde el 21 de octubre hasta fines de noviembre.

La edificación que hoy alberga el Museo de Arte Colonial anteriormente fue el convento de la congregación franciscana, rol que cumplió hasta 1969 cuando fue declarado MHN. En su interior se conservan 42 lienzos de 1684 que narran la vida de San Francisco (CMN, 2017). Este Museo fue intervenido mediante la técnica de rayado, las consignas que se instalan apuntan a la recriminación del actuar de fuerzas de orden público, feminismo y colonización, destacando el tachado que se hace a la palabra "Colonial" del nombre del Museo en su entrada.

A inicios de diciembre se da curso al repintado con color gris de la fachada del museo y a la semana siguiente se adopta el color que tenía antes del estallido (blanco), quedando sólo las intervenciones que resultan difíciles de limpiar, como los rayados 
que están a un nivel más alto en relación a la escala humana y el de las letras metálicas de la palabra colonial. Esta limpieza no perdura y aparecen nuevos rayados que en las dos últimas semanas del año son borrados selectivamente con otro color (rojo), silenciando o censurando sólo las consignas que aluden al movimiento, al feminismo $\mathrm{y}$ al uso de la fuerza policial (Figura 6).
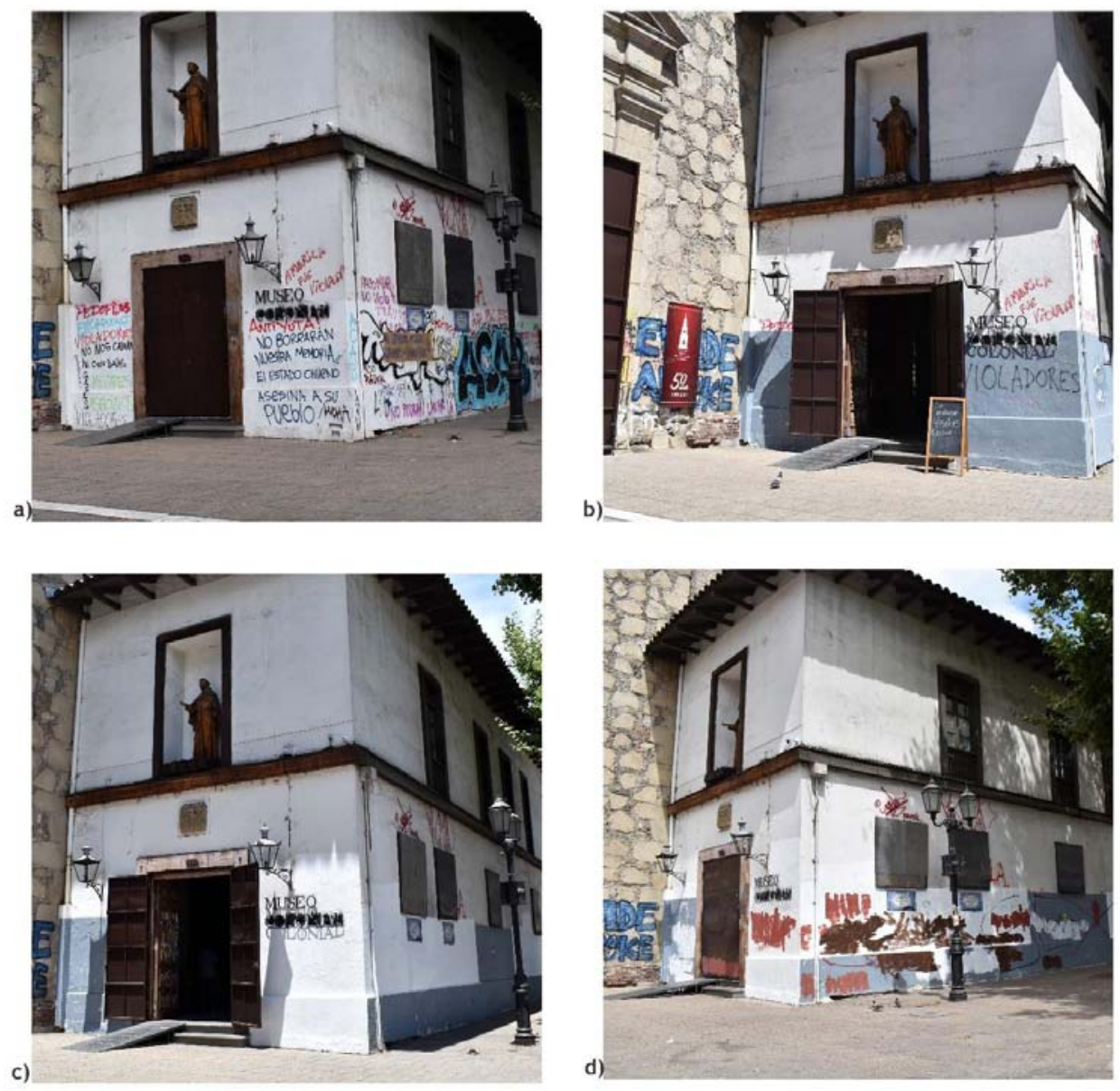

Figura 6. Intervenciones y repintados a la entrada del Museo Colonial. Fotografías tomadas a) 24-11-19, b) 04-12-19, c) 13-12-19 y d) 29-12-19. 
En términos generales, el Museo Colonial no se configura como un espacio en disputa en términos materiales, pese a que los inmuebles contiguos sí lo sean. Ciertamente, el Barrio París-Londres es escenario de distintas intervenciones mediante rayados y carteles, las que en su mayoría apuntan a visibilizar demandas sociales y a denunciar abusos perpetrados por carabineros. Así mismo destacan las consignas sobre exigencias feministas y veganismo, las que sólo en esta Zona Típica son protagónicas.

En lo que refiere al Museo Histórico, este edificio albergó la sede de la Real Audiencia y posterior a la independencia, se convirtió en la sede del Primer Congreso Nacional y Casa de Gobierno hasta el año 1845. Posteriormente el edificio continuó cumpliendo funciones públicas y en 1982 pasó a ser la sede del Museo Histórico Nacional, fue declarado Monumento Histórico en 1951 (MHN, s.f.). Este inmueble prácticamente no presentó intervenciones y sólo en la última semana del año se registraron dos rayados que referían a las fuerzas de orden público, por lo tanto, su fachada no se configuró como un espacio en disputa, como si lo fue la Zona Típica en la cual se ubica, a saber, la Plaza de Armas.

En relación a lo enunciado, ambos inmuebles difieren en cuanto a la persistencia de las labores de limpieza, ya que mientras el Museo Colonial es constantemente intervenido y como consecuencia repintado; el Museo Histórico se mantiene sin mayores intervenciones. No obstante, en ambos edificios y zonas destacan las consignas que cuestionan el actuar de carabineros, las cuales van aumentando a medida que se hacen públicas las denuncias que dejan en evidencia estas vejaciones.

d) Inmuebles que son Iglesias

Las iglesias revisadas fueron la Iglesia y el Convento de San Francisco emplazados en La Alameda y la Catedral de Santiago, ubicada en la Plaza de Armas, ambos declarados MHN en 1951. Durante el estallido social, la Iglesia de San Francisco se mantuvo cerrada y reabrió sus puertas en noviembre, en cambio, la Catedral estuvo abierta las primeras semanas, protegida por vallas papales y carabineros que resguardaban la Plaza de Armas, ante las manifestaciones sostenidas, fue cerrada y sus entradas protegidas con placas metálicas.

En el emplazamiento de la actual Catedral de Santiago se erigió el primer templo religioso de la ciudad en 1541, que posteriormente fue destruido en un alzamiento indígena ese mismo año. Luego de que en 1561 el Papa Pío IV creara el Obispado de Santiago, la iglesia reconstruida fue consagrada como Catedral. La construcción actual se remonta al año 1745 siendo terminada en 1909 (CMN, 1951a). En el marco del estallido social, la Catedral de Santiago sólo es intervenida durante los primeros días, únicamente con consignas que denuncian los abusos sexuales perpetrados por sacerdotes y posteriormente aparece un único rayado en alusión a Catrillanca. Dichas intervenciones, realizadas sobre el muro de piedra no son borradas durante el año, como sí lo son las intervenciones realizadas en la Plaza de Armas. 
La iglesia y Convento de San Francisco también es uno de los templos católicos más antiguos del país, su origen se remonta a los albores de la conquista española. Durante 1618 se levanta una nueva edificación a cargo de la orden franciscana (Jorquera, 2014), la que por dificultades económicas pone a la venta estos terrenos y parte de los claustros interiores del convento son demolidos. Hacia 1960 el Comité Pro-Restauración de San Francisco recupera el patrimonio de la Iglesia, la que actualmente se encuentra contigua al Museo de Arte Colonial (CMN, 1951b).

La Iglesia de San Francisco se constituyó como un espacio en disputa en términos materiales e ideológicos, donde podemos observar prácticas sucesivas de limpieza, reintervenciones, censura y silenciamiento, puesto que a inicios de diciembre se repinta con el color que tenía antes del estallido (rojo) y en las últimas semanas del año se borran selectivamente sólo algunas intervenciones. La técnica de intervención más destacada fue el rayado, con tecnologías tales como spray y bolígrafos, a medida que avanza el tiempo, el cartel también se posiciona como una técnica efectiva, pues logran resistir las inclemencias del paso del tiempo y al borrado, apareciendo en distintos formatos.

Las consignas que más destacaron fueron las denuncias contra las malas prácticas sacerdotales (robos y abusos sexuales), de hecho, luego del repintado general de la iglesia, estas consignas son las primeras en reaparecer y en las dos últimas semanas del año se silencian, pintándolas con color blanco o rojo. Al mismo tiempo aparecen intervenciones alineadas a la religión católica, las que llaman a la paz y comunión, aunque poseen una muy baja visibilidad puesto que se realizan con bolígrafos (Figura 7). 

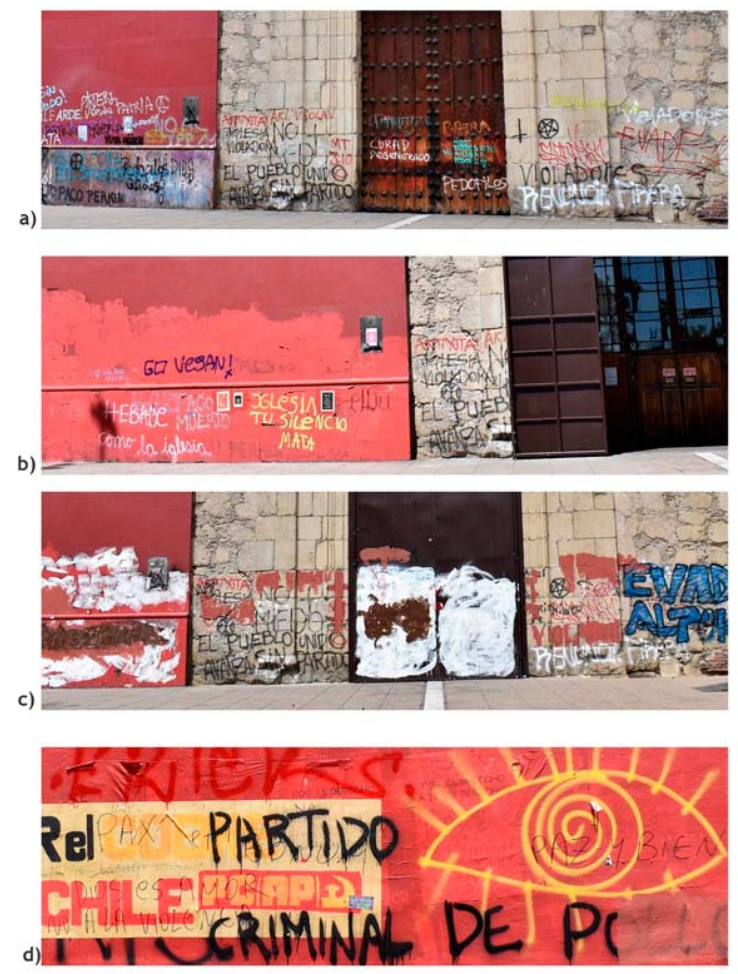

Figura 7. Detalle de intervenciones en Iglesia y Convento San Francisco. a) Destacan denuncias sobre abusos sexuales y malas prácticas sacerdotales (01-11-19), b) reaparecen luego del primer repintado general (04-12-19) y c) son censuradas a fin de año (29-12-19). d) aparecen consignas que defienden los valores de la Iglesia (2212-19).

Entre las otras consignas, también destacan aquellas que denuncian el uso de la violencia por carabineros y referencias a pueblos originarios, algunas en mapudungún y otras vinculadas a demandas por reconocimiento territorial. A un mes del estallido, nos encontramos con consignas que nombran a las víctimas y hacia fin de año se posicionan fuertemente consignas relativas a veganismo y feminismo, y los derechos en estas materias, las cuales ya se encontraban presentes en la Zona Típica del Barrio París-Londres desde mucho antes. También, en la Iglesia de San Francisco aparecen otros rayados que generan controversias, específicamente aquellos de contenido xe nófobo. Al respecto, aunque estas consignas no son increpadas de manera directa, se interviene sobre ellas, pese a que parte de los muros del convento se encuentran disponibles (Figura 8). 

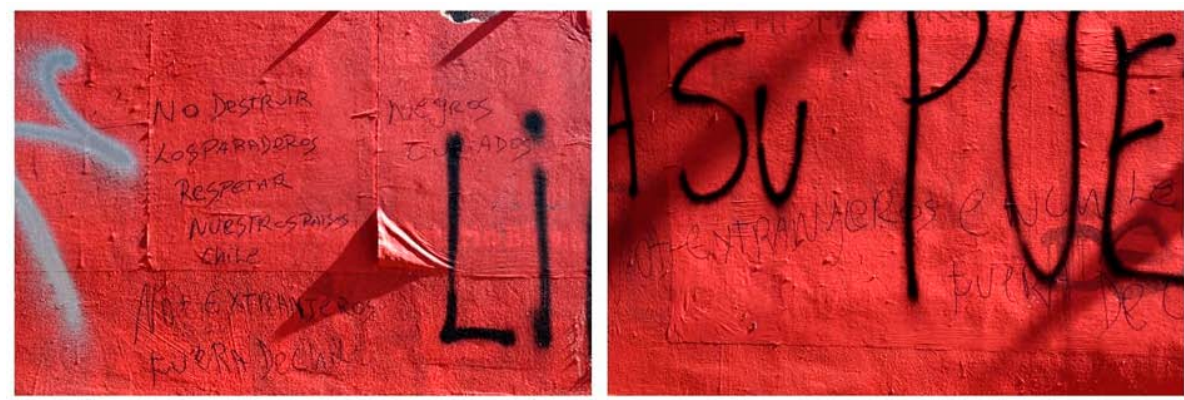

Figura 8. Detalle de rayados xenófobos sobre pared repintada y reintervenida de Iglesia y Convento de San Francisco (08-12-19).

Como podemos ver, en la Iglesia y Convento de San Francisco y sus alrededores ocurre una disputa ideológica y material del espacio, el cual se encuentra proclive a ser apropiado y resignificado por distintos autores. Aunque en ambas iglesias se denuncian los abusos sexuales cometidos por la institución, lo que más sobresale, es que pareciera que en un espacio éstas resultan más incómodas que en el otro. Así, para el caso de la Catedral las consignas perduran hasta fin de año, mientras que en la Iglesia y Convento de San Francisco se establece una dinámica en la que se borran y reaparecen constantemente.

e) Inmuebles con función educativa

Las edificaciones registradas fueron la Casa Central de la Universidad de Chile y la Biblioteca Nacional, declaradas MHN en 1974 y 1976 respectivamente, ambas emplazadas en La Alameda. La Casa Central de la Universidad de Chile se inserta en la Zona Típica del Sector de las calles Nueva York, La Bolsa y Club de la Unión, permaneció tomada por estudiantes desde el 21 de noviembre hasta los primeros días de diciembre, posterior a esto reabre sus puertas. Por su parte, la Biblioteca Nacional, en la Zona Típica Santa Lucía, permaneció cerrada durante el periodo de registro y sus trabajadores estuvieron en paro desde el 21 de octubre hasta finales de noviembre.

La casa central de la Universidad de Chile es una edificación de estilo neoclásico que data de 1872, hasta comienzos del siglo XX albergó a la mayoría de las facultades de la Universidad, pero en la actualidad el edificio está reservado para departamentos administrativos y actividades oficiales (CMN, 1974b). En lo que concierne al tipo de intervención realizada, destacan el rayado y los carteles, ya sea impresos o de confección manual, además de varios lienzos de gran tamaño (Figura 9). 

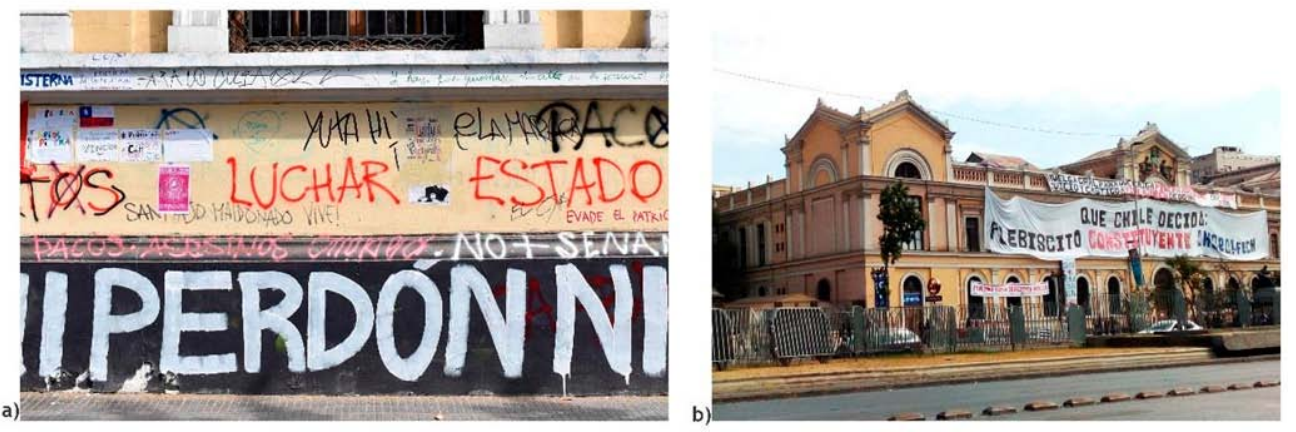

Figura 9. Intervenciones más destacadas en la casa central de la Universidad de Chile. a) Rayados y carteles de confección casera e impresos (11-11-19) y b) lienzos de gran tamaño (24-11-19).

En cuanto a las consignas, las más aludidas refieren al Estado y al presidente, aquellas que recriminan el actuar de las fuerzas de orden público y otras vinculadas a nuestras raíces latinoamericanas. Además, desde las primeras semanas se identifican consignas que exigen una asamblea constituyente y nueva constitución, así como las que esbozan temáticas vinculadas al feminismo, las que aparecen primero en este inmueble antes que en otros. Sobresale que una de las formas usadas para enunciar consignas, se vale de tonos poéticos o narrativos (Figura 10).
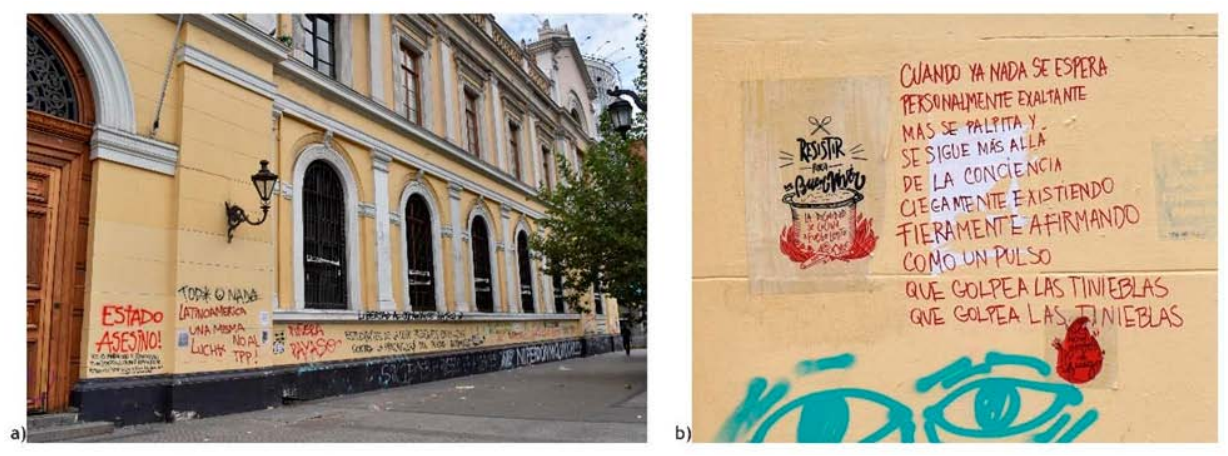

Figura 10. Ejemplos de consignas más aludidas y destacadas desde las primeras semanas en la casa central de la Universidad de Chile (01-11-19). a) Alusiones al Estado, al gobierno y Latinoamérica. b) ejemplo de consigna en tono poético o narrativo.

El frontis de la Casa Central de la Universidad de Chile es un espacio intensamente intervenido, se identifica una interacción entre rayados y la ocupación de niveles más altos que la escala humana. Además, también se interviene la estatua de Andrés Bello frente a su entrada principal, encapuchándola y rayando su pedestal. A un mes de las manifestaciones y posterior al anuncio del plebiscito por una nueva constitución y el 
“Acuerdo por La Paz", este inmueble se repinta por indicación de autoridades universitarias y al día siguiente amanece rayado con consignas contrarias al movimiento, las que son borradas durante ese mismo día por la organización estudiantil (Fech).

Durante los primeros días de diciembre comienzan a aparecer nuevas consignas relativas a la Dictadura, a las víctimas del estallido social y algunas de carácter personal. La última semana del año hay una nueva intervención a la estatua de Andrés Bello, colocando un collar confeccionado con casquillos de lacrimógenas. En base a lo antes mencionado, podemos notar que, en el frontis de la Casa Central de la Universidad de Chile, se evidencia una cronología entre el movimiento y las intervenciones plasmadas.

El inmueble que ocupa la Biblioteca Nacional fue inaugurado en 1925 para tal fin, pero el depósito bibliográfico nacional data de 1813 cuando se conformó su fondo mediante la donación o adquisición de colecciones. El depósito fue fortalecido con la nueva Ley de Registro de Propiedad Intelectual, que tuvo como corolario la creación de la DIBAM (Dirección de Bibliotecas, Archivos y Museos) en 1929 (CMN, 1976c).

Las intervenciones en este inmueble corresponden a carteles y rayados realizados con distintas técnicas, además de dos lienzos grandes dispuestos en su entrada principal, el primero es puesto a un mes del estallido y es reemplazado por otro en la segunda quincena de diciembre (Figura 11). En la Biblioteca las consignas que más aparecen aluden al actuar de carabineros, Dictadura e incitación a la lucha, además, se critican las condiciones laborales de los trabajadores de la biblioteca y el proyecto de la nueva Ley de Patrimonio.
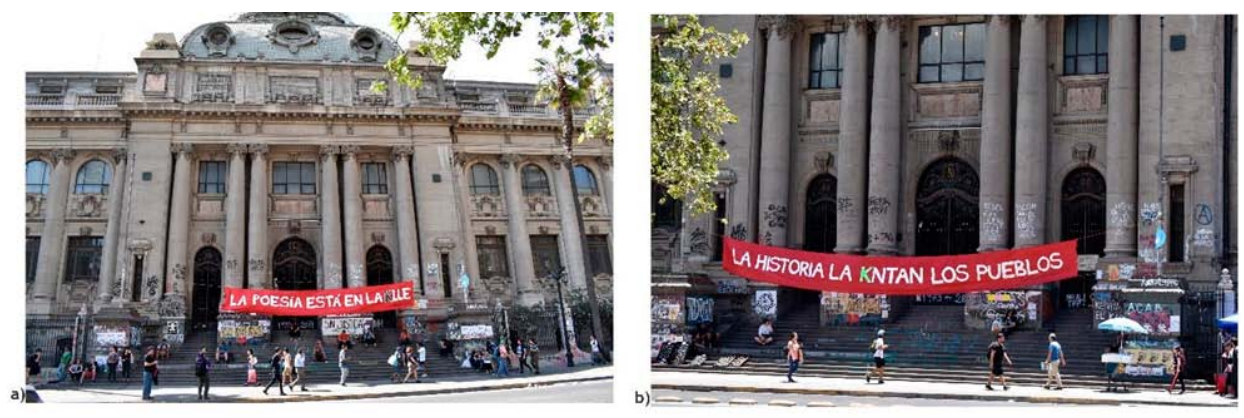

Figura 11. Intervenciones en Biblioteca Nacional. a) Lienzo que dice: "la poesía está en la calle" (18-11-19) y b) lienzo que dice: "la historia la kantan los pueblos" (13-1219).

En este espacio se observa una relación con la cronología del movimiento, no obstante, desde la segunda quincena de diciembre y una vez que la estación de Metro Santa Lucia-que tiene salida a la Biblioteca-comienza a funcionar, se detienen las intervenciones. Hacia finales de año la fachada de la Biblioteca Nacional comienza a dejar atrás parte de las intervenciones que se plasmaron, con el retiro de los lienzos y 
el borrado de algunas consignas. En base a lo anterior, podemos afirmar que la Biblioteca Nacional se configura como un espacio en disputa material, puesto que no sólo la fachada es utilizada de forma reiterada, también los espacios contiguos como la calzada, pilares, basureros y la escalera en la entrada del edificio. Al mismo tiempo, es el único MHN en el cual se discute la temática del patrimonio y en el que los carteles son más preponderantes que los rayados.

En suma, tanto en la Casa Central de la Universidad de Chile como en la Biblioteca Nacional se critica al Estado y al presidente, pero además en cada espacio se instalan demandas propias en cuanto a su rol social. En el caso de la Universidad de Chile se exalta su rol educativo y su compromiso con la educación pública, mientras que en la Biblioteca Nacional se establece una crítica y postura respecto a la nueva Ley de Patrimonio que se encuentra en el Congreso para su revisión desde mediados del año 2019. Además, en ambos monumentos nos encontramos con tecnologías propias, tales como carteles caseros y lienzos.

\section{Lo que dicen los monumentos sobre sus ciudadanos / Lo que dicen los ciudadanos sobre sus monumentos}

a) ¿Cómo lo dicen?... ¿Qué dicen?

En términos generales, en las intervenciones a los MHN de Santiago, el rayado y el cartel fueron las técnicas predominantes y que perduran con el paso de las semanas. Respecto a lo que dicen las consignas inscritas, tanto en los MHN como en su Zona Típica, éstas se expresan en un tono de denuncia y/o demanda, salvo en los inmuebles que poseen una función educativa, donde las consignas adquieren un tono más poético, con alusiones al género narrativo y literario.

En las consignas inscritas en los MHN, se identifican tres alusiones mayoritarias: las que apuntan al rol del Estado, pueblos originarios y la recriminación al actuar de fuerzas de orden público. Pero al mismo tiempo, en todos los MHN revisados se identifican consignas propias que se relacionan específicamente con éstos, así, en el caso de las Iglesias se increpan los abusos sexuales y la institución eclesiástica, de hecho, en la Catedral es prácticamente el único tema al que se alude y en la Iglesia de San Francisco éstos tienen una predominancia considerable y reaparecen pese al constante borrado, a tal punto que en las últimas semanas son eliminados selectivamente, sin reparar en el acabado visual del monumento.

En el caso de los inmuebles con función educativa, más que un tipo de consigna predominante, se identificó una forma específica de enunciarlas. Quienes hacen uso de estos inmuebles (trabajadores y estudiantes) exponen su postura mediante lienzos que apoyan el estallido social y las demandas ciudadanas, además de expresar demandas propias. En el caso de la Universidad de Chile, estas estrategias de intervención y ocupación son prácticas ya instauradas para enunciar demandas sobre la educación 
pública (Fernández, 2019). De este modo, el rol de estos edificios no es criticado, sino que sirven de soporte para consignas que refieren al rol social que cumplen como promotores de la "cultura" y la educación.

En los inmuebles con funciones recreativas, administrativas y museos, se encuentran todo tipo de consignas y se alude a estos lugares y sus Zonas Típicas, en tanto corresponden al casco fundacional de la ciudad, sus funciones específicas no son increpadas. Aquí sobresalen consignas referidas a pueblos originarios, específicamente al pueblo Mapuche y la colonización, apelando al cuestionamiento de la historia oficial, el proceso de colonización y la fundación de Santiago, proceso que despojó a culturas de su territorio (Dávila et al., 2018).

Por lo tanto, el tipo de consignas plasmadas en los MHN se relaciona con los valores y significados con los que se asocian y en algunos casos las intervenciones están pensadas para cada espacio. Quienes ocupan los MHN como soporte de sus intervenciones son conscientes de la carga histórica, valórica y/o simbólica, aunque no necesariamente la comparten, lo cual es referido en las consignas inscritas en éstos.

b) El cuidado del patrimonio: Un asunto de Estado

Las intervenciones, como forma de apropiación y uso de los MHN, coexisten con el discurso levantado desde el Estado y sus organismos representativos, que establecen una concepción normativa del patrimonio, donde prima la gestión conservacionista. Debido a esto, se instaló una preocupación constante por el estado del patrimonio en el estallido social, a la que se sumaron diversos agentes. En la comuna de Santiago se evidenciaron dos grandes hitos de limpieza: a un mes del estallido luego que se anunciara el «acuerdo por la paz» que convoca a un plebiscito ciudadano respecto al cambio de Constitución, y al acercarse las fiestas de fin de año. Mientras que el primero se relaciona con una actitud del gobierno en dar por finalizada las manifestaciones con la subsecuente criminalización de éstas; con las fiestas se pretende la "normalización" de la ciudad junto a la reparación de infraestructura pública y repintado, bajo una lógica de "aquí no ha pasado nada", intentando eliminar toda huella material de la protesta social, como otra forma de represión de la misma.

No obstante, las dinámicas de limpieza se enfrentan a la reintervención, entre las que se hace referencia al borrado o incluso aparecen otras que van en contra de consignas enunciadas en el estallido. De esta manera, se hace patente la imposibilidad de silenciar los muros, por lo que en algunos casos se recurre a la táctica del borrado selectivo aplicado sólo a algunas consignas. Esto evidencia que más allá del acabado estético del monumento, lo que finalmente resulta más incómodo o molesto es lo que se dice en éstos, sobre todo si increpa directamente al monumento, el rol que cumple o los valores que representa, como por ejemplo, lo enunciado en la Iglesia y Convento de San Francisco o las incesantes apariciones de la palabra Huelén en el Cerro Santa Lucía. 
También se identificó una preocupación constante por los inmuebles ubicados en La Alameda, principal avenida del sector cívico y fundacional de la capital, que al ser eje de las manifestaciones, se mantuvo en disputa constantemente, identificándose superposición de rayados y sucesivas labores de limpieza que poco duraron. En cambio, al alejarnos de esta avenida, a poco más de un mes del estallido las intervenciones decayeron y no se observaron acciones de limpieza. Ya una vez terminado el registro y con el período de vacaciones, se agudizan las labores de limpieza, aprovechando la cuarentena por la pandemia mundial del Covid-19, donde se priorizan la restauración del patrimonio a pesar de los problemas económicos y sociales que trajo consigo.

$\mathrm{Al}$ respecto, podemos ver que la ubicación y visibilidad de los espacios tuvo incidencia en el grado de intervención y en consecuencia, en los trabajos de limpieza posteriores. Estas acciones dan cuenta de una disputa ideológica y material por ocupar los muros y los MHN, ya que por un lado impera una visión conservacionista y proteccionista, la cual invisibiliza otros usos, apropiaciones o hibridaciones que poseen en el presente (Hernández, 2008).

c) Ser en el patrimonio: el patrimonio presente

Ahora bien, considerando el tipo de consigna plasmada en los $\mathrm{MHN}$, las que refieren a violencia se instalan como un tópico recurrente y se agudizan con dos momentos relacionados a la cronología del estallido, predominan las denuncias al actuar de carabineros y la alusión a sujetos que han sido históricamente víctimas de violencia: mujeres y pueblos originarios. Aunque ambos y ambas agentes cobran protagonismo desde el inicio del estallido, hay dos hitos con los cuales se intensifica su presencia a nivel de consignas: la conmemoración del asesinato de Camilo Catrillanca el 14 de noviembre y a la intervención del colectivo "Las Tesis" que se replica en Santiago desde el 25 de noviembre.

El rostro y nombre de Camilo Catrillanca se toman los muros, igualmente aparecen consignas que exigen justicia y condenan el abuso de la fuerza policial relacionada a su homicidio. Al respecto, podemos ver cómo Catrillanca se convierte en un ícono de la represión y violencia histórica hacia el pueblo Mapuche, así como de la violencia policial en Chile, lo que quedó aún más en evidencia en el estallido social mediante las acciones represivas, cuestionadas por organismos que velan por los DDHH (Peñaloza, 2019).

De este modo, las referencias al pueblo Mapuche y su autonomía territorial se enuncian como una de las grandes consignas de este estallido, donde el Kultrún es protagonista y el mapudungún aparece en las calles. En base al comportamiento de los muros de los MHN, podemos afirmar que existe una reivindicación de los significantes de la cultura Mapuche, e independiente de quienes los enuncien, con la circulación de sus símbolos afirman esta identidad en la urbe (Gundermann, 2013). Estas consignas toman visibilidad en el patrimonio como lugar de disputa ideológica 
y material, reclamando significados que han sido omitidos por el discurso oficial, el cual también ha ignorado su reconocimiento y negado su participación real en políticas de Estado (Caniuqueo, 2006).

Las alusiones a pueblos originarios son más abundantes en los MHN relacionados directamente a la historia fundacional de la ciudad, como por ejemplo, con los rayados de Kultrún en la Plaza de Armas y el Cerro Santa Lucía. Por lo tanto, mediante las intervenciones realizadas en los MHN de Santiago, la ciudad y su patrimonio se reclaman simbólicamente, dando cuenta que los pueblos originarios estuvieron y están presentes en ésta.

También nos encontramos con alusiones a la colonización y descolonización, no sólo en relación al pasado, sino que también a la colonización global actual. En efecto, el neoliberalismo, al abrir la economía a lo global, somete al Estado a intereses transnacionales, constituyéndose así como una neocolonización que no ha hecho más que aumentar la desigualdad social (Vargas, 2007). Entonces, la noción de lo público o común se diluye, lo cual incluye al patrimonio como bienes de interés público y representantes de una supuesta identidad común (Criado-Boado y Barreiro, 2013), la que también se desvanece, puesto que se cuestiona la historia y valores que los consolidan. Los MHN responden y encarnan una narrativa oficial que las élites han impuesto, usada para distinguirse socialmente y valiéndose de construcciones que encarnan la "tradición, belleza y superioridad" de los cánones estilísticos europeos (Vergara, Bergot y Vizcaino, 2015).

Por otro lado, las consignas feministas también se toman los muros y aumentan desde que se replicó la performance de «Las Tesis» en varias ciudades de Chile y el mundo, intervención que invita a las mujeres a manifestarse en las calles, denunciando los abusos, exclusión y violencia a la que históricamente han sido sometidas.

En base a lo anterior, podemos decir que los MHN y sus Zonas Típicas como emblemas de poder estatal, nacional e identitario, también funcionan como soporte de enunciación para manifestar una opinión ciudadana sobre la realidad país, exponiendo en el espacio público la violencia, omisión y exclusión de agentes marginados de nuestra historia. Los habitantes y transeúntes de Santiago plasman en los muros un sentir sobre sí mismos y sobre la relación con su patrimonio en el presente, visiones que en algunos casos difiere de la oficial. Lo anterior deja en evidencia que las valoraciones respecto al patrimonio no siempre son comunes y compartidas, en tanto dispositivos de memoria y poder, pueden variar de acuerdo a cada contexto específico, e incluso convertirse en patrimonios incómodos (Criado-Boado y Barreiro, 2013; Harrison, 2013; Meskell, 2002).

Por tanto, mientras el Estado exalta su pasado y utiliza la memoria como una herramienta disuasiva (Todorov, 2000); quienes se manifiestan, intervienen los MHN y sus alrededores como parte de un movimiento mayor que tiene relación con el uso 
actual de la ciudad, otorgándoles una nueva capa de sentido que se suma a las ya existentes (Jelin y Langland, 2002). Lo anterior queda en evidencia cuando en las paredes semi pulcras del repintado, se raya: "borrarán los muros, pero no la historia" o "los muros son nuestros".

d) Los muros son nuestros

Los MHN y su Zona Típica se configuran como un espacio en disputa donde se vislumbra la violencia y normatividad que el poder instaura, ya sea mediante violencia física o simbólica, con discursos que criminalizan a la ciudadanía que se manifiesta, invisibilizando las demandas sociales y sin reparar en cómo la resignificación ciudadana de los monumentos instala una nueva forma de relacionarse con éstos. El Estado norma, mutila, agrede y vandaliza los cuerpos que se presentan en las calles; sus huellas materiales son borradas, limpiadas, censuradas o criminalizadas, imponiendo una "normalidad" e instalando un discurso beligerante contra los y las manifestantes (Navarro y Tromben, 2019; Peñaloza, 2019).

En esta lógica normativa, las calles se transforman en un bien preciado, pues permite la visibilidad de las demandas, denuncias y opiniones ciudadanas. Si bien desde antes del estallido las calles sirvieron como soporte de diversas expresiones, en este contexto, los muros de los MHN quedan al servicio de la ciudadanía que los ocupa intensivamente. La ciudad y los MHN están siendo ocupados como lugar de enunciación y comunicación, se resignifican, dejando atrás su pasado como inmuebles ocupados por el poder y las élites, o como parte de las calles que fueron censuradas y reprimidas durante la Dictadura, las que vuelven a gritar y ser testigos materiales en manifestaciones (Rojo, 2008).

Las calles no sólo nos permitieron leer parte de las demandas ciudadanas, sino que también posibilitaron entender cómo procedieron las prácticas de censura, silenciamiento y sus efectos. La ciudad como espacio de enunciación está abierta a distintas opiniones sobre un mismo fenómeno, mostrando la inherente disputa que subyace al patrimonio, muchas veces oculta en discursos hegemonizantes.

En el caso revisado, las consignas escritas dan cuenta que existe un posicionamiento general (aunque no único), que deja al descubierto un sentir común en torno a la historia reciente de nuestro país y ciertas narrativas excluidas del patrimonio, lo que puede posibilitar un "hacer común" respecto a éste, y por ende, una construcción de comunidad con todos, todas y todes quienes se han visto marginados y marginadas en narrativas oficiales (Harris, 2012). En este sentido, los MHN permiten anclar una identidad autónoma que los grupos humanos determinan mediante su uso y también posibilitan una experiencia compartida en relación a prácticas, acciones y afecciones en torno a éstos, evidenciada en la expresión, rebelión y proyección de un futuro compartido. 


\section{Conclusión}

De acuerdo a las demandas y consignas materializadas en las calles y en los monumentos revisados, se han establecido temáticas transversales relacionadas con la violencia ejercida por el Estado en distintas dimensiones y con los sujetos que históricamente han sido marginados o víctimas de esta violencia. En el contexto histórico del estallido social, los muros de los MHN no quedan indiferentes a nadie y las intervenciones en éstos tienen diversas afecciones para distintos agentes: los rayan, limpian y vuelven a intervenir, pero sobretodo, los resignifican.

A razón de lo anterior los MHN pasan a encarnar simbolismos, sentidos específicos y situados, para quienes habitan y transitan por la ciudad, basados en criterios estéticos, conservadores e ideológicos, entre otros. De esta manera se enuncian sus características normativas o subversivas, como un espacio también de poder simbólico y un debate por quien tiene la última palabra, o ejecuta el último rayado o pintado. Por tanto, antes que vandalismo, las intervenciones a estos inmuebles forman parte de un uso específico en un momento determinado, incorporan nuevos sentidos, los saca de su pasado inmaculado y los inserta en el presente, cuestionando la representatividad del gobierno, el sistema político-económico y los valores y usos atribuidos a este patrimonio.

En base a la actitud que tomó el gobierno ante el estallido social, con la omisión de las demandas y criminalización de la protesta, es posible aventurar que el ímpetu y descontento que en primer momento desencadenó este movimiento, continuará y que por lo tanto la calle seguirá ocupándose. En efecto, en el desarrollo de este escrito y durante el periodo estival en que las manifestaciones disminuyeron, se agudizaron las labores de limpieza y reparación en gran parte de los MHN, así como también se realizó el plebiscito que aprobó el proceso de redacción de una nueva Constitución, el cual contó con una gran participación ciudadana, pese a su aplazamiento por la pandemia del Covid-19. Lo anterior no sólo da cuenta de la importancia que adquiere el patrimonio como herramienta de control estatal, sino que también exhibe una manera en que el poder invisibiliza las relaciones establecidas entre quienes habitan la ciudad, con su historia y patrimonio. Esto cobra aún más relevancia si sumamos los cuestionamientos que ha tenido el proyecto de una nueva Ley de Patrimonio, actualmente en revisión por el Congreso.

Las huellas materiales que dejan las intervenciones en los MHN son el resultado de un proceso en curso que forma parte de una historia aún no vivida, aún no contada y aún no construida. Los MHN de la comuna de Santiago nos introducen a la búsqueda de una ciudad más democrática, que reconozca como agentes a los sujetos históricamente silenciados, y donde el pasado represivo y violento que dejó como legado la dictadura, no puede repetirse ni formar parte del presente. 
Así la resignificación del patrimonio es una resignificación identitaria de quienes se relacionan con éste, donde determinan quiénes son y la incidencia que puede tener en su presente las narrativas impuestas como valores a partir de estos inmuebles. En este sentido, el patrimonio no deja de serlo, más bien adquiere una nueva forma de ser patrimonio, según la cual se vuelve valioso debido a las relaciones en las que estos bienes están insertos, posibilitando la proyección de una comunidad con más justicia y voz para todos, todas y todes.

\section{Referencias}

Adriazola, Álvaro (2019, 12 de Noviembre). Crisis en Chile. Iberoamérica Social. Recuperado de https://iberoamericasocial.com/crisis-en-chile/.

Aliste, Enrique (2008). Huellas en la ciudad: territorio y espacio público como testimonio para una geografía social. En X. Póo (ed.), Transformaciones del espacio público (ponencias II), cátedra Chile-Francia (pp.49-58). Santiago: Universidad de Chile. Recuperado de https://www.uchile.cl/documentos/libro-transformaciones-del-espacio-publico-pdf_53152_0_1824.pdf.

Augé, Marc (1992). Los no lugares: Espacios del anonimato. Una antropología de la sobre modernidad. Barcelona: Gedisa.

Ayala, Patricia (2014). Patrimonialización y Arqueología Multicultural en San Pedro de Atacama (Norte de Chile). Estudios Atacameños (49):49-64. Recuperado de https:// scielo.conicyt.cl/scielo.php?script=sci_arttext\&pid=S0718-10432014000300005.

BBC (2019, 6 de diciembre). Las Tesis sobre «Un violador en tu camino»: Se nos escapó de las manos y lo hermoso es que fue apropiado por otras. Recuperado de https:// www.bbc.com/mundo/noticias-america-latina-50690475.

Benavides, Alfredo (1988 [1941]). La arquitectura en el virreinato del Perú y en la capitanía general de Chile. Santiago: Andrés Bello.

Boccara, Guillaume y Patricia Ayala (2011). Patrimonializar al indígena: Imaginación del multiculturalismo neoliberal en Chile. Les Cahiers des Ameriques Latines (67): 207-230. Recuperado de https://www.researchgate.net/publication/269498527_ Patrimonializar_al_indigena_Imagi-nacion_del_multiculturalismo_neoliberal_ en_Chile.

Bourdieu, Pierre (1991). El sentido práctico. Buenos Aires: Taurus.

Calvento, Mariana (2006). Fundamentos teóricos del neoliberalismo: su vinculación con las temáticas sociales y sus efectos en América Latina. Revista de Ciencias Sociales Convergencia, 41-59. Recuperado de http://www.scielo.org.mx/scielo. php?script=sci_arttext $\&$ pid=S1405-14352006000200002. 
Caniuqueo, Sergio (2006). Siglo XX en Gulumapu: de la fragmentación del Wallmapu a la unidad nacional Mapuche. 1880-1978. En P. Mariman. Escucha winka. Cuatro ensayos de historia nacional mapuche y un epílogo sobre el futuro (pp. 129-217). Santiago: Lom Ediciones.

Castillo-Gallardo, Patricia, Nicolás Peña, Cristóbal Rojas Becker y Génesis Briones (2018). El pasado de los niños: Recuerdos de infancia y familia en dictadura (Chile, 1973-1989). Psicoperspectivas, 17(2). Doi: https://doi.org/10.5027/psicoperspectivas-vol17-issue2-fulltext-1180.

Chilevisión noticias (2019, 24 de octubre). Qué significa ACAB, el rayado que aparece después de las protestas. Recuperado de https://www.chvnoticias.cl/nacional/ significado-acab-rayado-protestas_20191024/.

Consejo de Monumentos Nacionales (1951a). Catedral de Santiago. CMN. Recuperado de https://www.monumentos.gob.cl/monumentos/monumentos-historicos/ catedral-santiago.

Consejo de Monumentos Nacionales (1951b). Iglesia y Convento de San Francisco. CMN. Recuperado de https://www.monumentos.gob.cl/monumentos/monumentos-historicos/iglesia-convento-san-francisco.

Consejo de Monumentos Nacionales (1974a). Teatro Municipal de Santiago. CMN. Recuperado de https://www.monumentos.gob.cl/monumentos/monumentoshistoricos/teatro-municipal-santiago.

Consejo de Monumentos Nacionales (1974b). Edificio de la Casa Central de la Universidad de Chile. CMN. Recuperado de https://www.monumentos.gob.cl/monumentos/monumentos-historicos/edificio-casa-central-universidad-chile.

Consejo de Monumentos Nacionales (1976a). Correo Central. CMN. Recuperado de https://www.monumentos.gob.cl/monumentos/monumentos-historicos/correocentral.

Consejo de Monumentos Nacionales (1976b). Municipalidad de Santiago. CMN. Recuperado de https://www.monumentos.gob.cl/monumentos/monumentos-historicos/municipalidad-santiago.

Consejo de Monumentos Nacionales (1976c). Biblioteca Nacional. CMN. Recuperado de https://www.monumentos.gob.cl/monumentos/monumentos-historicos/ biblioteca-nacional.

Consejo de Monumentos Nacionales (2017). Iglesia y Convento de San Francisco fija límites. CMN. Recuperado de https://www.monumentos.gob.cl/servicios/decretos/14_2017.

Consejo de Monumentos Nacionales (2020a, Enero). Estadísticas de Monumentos Nacionales declarados por decreto. CMN. Recuperado de https://www.monumentos.gob.cl/monumentos. 
Consejo de Monumentos Nacionales (2020b, 16 de Enero). $82 \%$ de avance registra catastro georreferenciado de bienes patrimoniales alterados para enfrentar recuperación. CMN. Recuperado de https://www.monumentos.gob.cl/prensa/noticias/82avance-registra-catastro-georreferenciado-bienes-patrimoniales-alterados.

Consejo de Monumentos Nacionales (s.f.). Zonas Típicas. CMN. Recuperado de https://www.monumentos.gob.cl/categoria-monumentos/zonas-tipicas.

Correa, Carlos (2019, 11 de noviembre). Chalecos Amarillos. La Tercera. Recuperado de https:/www.latercera.com/opinion/noticia/chalecos-amarillos/895805/.

Criado-Boado, Felipe y David Barreiro (2013). El patrimonio era otra cosa. Estudios Atacameños, 45, 5-18. Recuperado de https://scielo.conicyt.cl/pdf/eatacam/n45/ art02.pdf.

Dávila, Cristian, Constanza Cortés, Andrea Martínez, Juan Hermosilla, Nicole Fuenzalida y Daniel Pavlovic (2018). Interacción social al sur del Collasuyu. Alfarería funeraria del periodo tardío (1400-1536 dc) en la cuenca Maipo-Mapocho. Revista Chungará, 50 (4). Recuperado de http://www.chungara.cl/Vols/2018/AOP/AOPDAVILA_ET_AL.pdf.

Duarte, Patricio (2003). Reflexión sobre una intervención histórica en la ciudad de Santiago: El caso del cerro Santa Lucía. Revista de Urbanismo (7). Recuperado de https://iamr.uchile.cl/index.php/RU/article/view/6211/11827.

Fair, Hernán (2008). El sistema global neoliberal. Revista Polis 7 (21), 229-263. Recuperado de https://scielo.conicyt.cl/scielo.php?script=sci_abstract\&pid=S071865682008000200012\&lng=es\&nrm=iso.

Fernández, Roberto (2019). Marchas y conmemoraciones. Santiago y el centro histórico. En F. Márquez (ed.), Patrimonio. Contranarrativas urbanas (pp. 115-129). Santiago: Universidad Alberto Hurtado.

García Canclini, Néstor (1995). Consumidores y ciudadanos. Conflictos multiculturales de la globalización. México: Grijalbo.

Gundermann, Hans (2013). Procesos étnicos y cultura en los pueblos indígenas de Chile. Alpha 36, 93-108. Recuperado de https://scielo.conicyt.cl/scielo. php?script=sci_arttext\&pid=S0718-22012013000100007.

Gross, Patricio (1991). Santiago de Chile (1925-1991): planificación urbana y modelos políticos. Revista de Estudios Urbanos Regionales, 17 (52/53): 27-52. Recuperado de https://www.eure.cl/index.php/eure/article/view/1073.

Hamilakis, Yannis (ed.) (2007). Cap. 1. Memories cast in marble: Introduction. En The Nation and Its Ruins. Antiquity, Archaeology, and National Imagination in Greece. Oxford: Oxford University Press. 
Harris, Oliver (2012). (Re)assembling Communities. Journal of Archaeological Method and Theory 21, 76-97. Doi:10.1007/s10816-012-9138-3.

Harrison, Rodney (2013). Heritage. Critical Approaches. London: Routledge.

Hernández, Gil-Manuel (2008). Un zombi de la modernidad: El patrimonio cultural y sus límites. La Torre del Virrey, 5, 27-38. Recuperado de https://core.ac.uk/download/pdf/70990155.pdf.

Instituto Nacional de Estadísticas (2017). Síntesis de Resultados Censo 2017. INE. Recuperado de https://www.censo2017.cl/.

Jelin, Elizabeth y Victoria Langland (2002). Introducción: Las marcas territoriales como nexo entre pasado y presente. En Monumentos, memoriales y marcas territoriales. Madrid: Siglo XXI.

Jorquera, Natalia (2014). Culturas constructivas que conforman el patrimonio chileno construido en tierra. Revista AUS (16), 28-33. Recuperado de http://revistas. uach.cl/pdf/aus/n16/art06.pdf.

Ley N 17.288 (2011). Ley No 17.288 de Monumentos Nacionales y Normas Relacionadas. Diario Oficial de la República de Chile, Santiago, Chile. Recuperado de https:// www.cultura.gob.cl/wp-content/uploads/2013/05/5_Ley-N\%C2\%B0-17.288-deMonumentos-Nacionales-y-Normas-Relacionadas.-2011.pdf.

Maderuelo, Javier (2001). El arte de hacer ciudad. En J. Maderuelo (ed.), Arte Público: Naturaleza y ciudad (pp. 17-52). Madrid: Fundación César Manrique.

Martínez, José Luis (2019). Entre estatuas y memoria. Rompiendo una(s) historia(s) de lo nacional. En M. Folchi (ed.), Chile despertó. Lecturas desde la Historia del estallido social de octubre (pp. 28-42). Santiago: Universidad de Chile. Recuperado de https://www.uchile.cl/publicaciones/160577/chile-desperto-lecturas-desdela-historia-del-estallido-social.

Márquez, Francisca (ed.) (2019). Patrimonio. Contranarrativas urbanas. Santiago: Universidad Alberto Hurtado.

Márquez, Francisca, Valentina Rozas y Rodolfo Arriagada (2014). El Lugar del patrimonio Dominante. ARQ (Santiago), (88): 56-65. Recuperado de https://dx.doi. org/10.4067/S0717-69962014000300010.

Matus, Mario (2019). Desigualdad: la grieta que fractura la sociedad chilena. En M. Folchi (ed.), Chile despertó. Lecturas desde la Historia del estallido social de octubre (pp. 59-69). Santiago: Universidad de Chile. Recuperado de https://www. uchile.cl/publicaciones/160577/chile-desperto-lecturas-desde-la-historia-delestallido-social.

Meskell, Lynn (2002). Negative Heritage and Past Mastering in Archaeology. Anthropological Quarterly, 75(3), 557-574. Doi: 10.1353/anq.2002.0050. 
Museo Histórico Nacional (s.f.). Historia Museo Histórico Nacional. Museo Histórico Nacional. Recuperado de https://www.mhn.gob.cl/sitio/Secciones/Quienessomos/Historia/.

Navarro, Federico y Carlos Tromben (2019). Estamos en guerra contra un enemigo poderoso, implacable: los discursos de Sebastián Piñera y la revuelta popular en Chile. Literatura y lingüística, (40): 295-324. Recuperado de https://scielo.conicyt. cl/scielo.php?script=sci_arttext\&pid=S0716-58112019000200295.

Paulsen, Alex (2014). Negocios inmobiliarios, cambio socioespacial y contestación ciudadana en Santiago poniente. El caso del Barrio Yungay: 2000-2013. En R. Hidalgo y M. Janoschka (eds.), La ciudad neoliberal. Gentrificación y exclusión en Santiago de Chile (pp. 76-98). Buenos Aires, Ciudad de México y Madrid. Santiago: Universidad Católica de Chile.

Peñaloza, Carla (2019). Derechos Humanos: el pasado que no pasa. En M. Folchi (ed.), Chile despertó. Lecturas desde la Historia del estallido social de octubre (pp. 7077). Santiago: Universidad de Chile. Recuperado de https://www.uchile.cl/publicaciones/160577/chile-desperto-lecturas-desde-la-historia-del-estallido-social.

Radio UChile (2019, 13 de noviembre). Padre de Camilo Catrillanca a un año de su asesinato: Hay mucha gente acompañando el dolor que tenemos. Recuperado de https://radio.uchile.cl/2019/11/13/padre-de-camilo-catrillanca-a-un-ano-de-suasesinato-hay-muc.

Rojo, Grinor (2008). Campo cultural y neoliberalismo en Chile. En X. Póo (ed.), Transformaciones del espacio público (ponencias II), cátedra Chile-Francia (pp.81-89). Santiago: Universidad de Chile. Recuperado de https://www.uchile.cl/documentos/libro-transformaciones-del-espacio-publico-pdf_53152_0_1824.pdf.

Salas, Gonzalo, Alfonso Urzúa, Antonia Larraín, Claudia Zúñiga, Marcela Cornejo, Vicente Sisto, Alba Zambrano, Marcelo Urra, Roberto Polanco-Carrasco, Alejandra Caqueo-Urízar, Claudia Pérez-Salas, Pedro Acuña y Walter Kühne (2019). Manifiesto por la Psicología en Chile: A propósito de la revuelta del 18 de Octubre 2019. Terapia psicológica, 37(3): 317-326. Recuperado de https://dx.doi. org/10.4067/S0718-48082019000300317.

Salazar, Gabriel (2019, 27 de octubre). El «reventón social» en Chile: una mirada histórica. Ciper. Recuperado de https://ciperchile.cl/2019/10/27/el-reventon-socialen-chile-una-mirada-historica/.

Smith, Laurajane (2006). Uses of Heritage. London: Routledge.

Soja, Edward (2011). Beyond Postmetropolis. Urban Geography, 32(4): 451-469. Doi: https://doi.org/10.2747/0272-3638.32.4.451. 
Todorov, Tzvtan (2000). Los abusos de la memoria. Barcelona: Paidós.

Vargas, José (2007). Liberalismo, Neoliberalismo, Postneoliberalismo. Revista Mad, (17): 66-89. Recuperado de http://www.facso.uchile.cl/publicaciones/mad/17/ vargas_04.pdf.

Vergara, Enrique, Solène Bergot y Marcelo Vizcaino (2014). Palacio Vergara: élite y arquitectura en Santiago a fines del siglo XIX. Arquiteturarevista, 10(2): 70-77. Doi: https://doi.org/10.4013/arq.2014.102.03.

Sobre los autores:

Natalie Martin es Magister en Arqueología y Arqueóloga. Investigadora independiente. Correo Electrónico: mnatalie.martinb@gmail.com. (D) https://orcid.org/00000001-5451-8444

Jimena TApia es Magister en Arqueología y Artista visual. Investigadora independiente. Correo Electrónico: jimenatp@gmail.com. (iD https://orcid.org/0000-00019637-0193 


\title{
CUHSO
}

Fundada en 1984, la revista CUHSO es una de las publicaciones periódicas más antiguas en ciencias sociales y humanidades del sur de Chile. Con una periodicidad semestral, recibe todo el año trabajos inéditos de las distintas disciplinas de las ciencias sociales y las humanidades especializadas en el estudio y comprensión de la diversidad sociocultural, especialmente de las sociedades latinoamericanas y sus tensiones producto de la herencia colonial, la modernidad y la globalización. En este sentido, la revista valora tanto el rigor como la pluralidad teórica, epistemológica y metodológica de los trabajos.

\author{
EDITOR \\ Matthias Gloël \\ COORDINADORA EDITORIAL \\ Claudia Campos Letelier \\ CorReCTOR DE ESTILO Y DISEÑADOR \\ Ediciones Silsag \\ Traductor, CORRECTOR LENGUA INGLESA \\ Aurora Sambolin Santiago \\ SITIO WEB \\ cuhso.uct.cl \\ E-MAIL \\ cuhso@uct.cl
}

LICENCIA DE ESTE ARTÍCULO

Creative Commons Atribución Compartir Igual 4.0 Internacional 